\title{
Anthropogenic sediment starvation forces tidal dominance in a mega-delta
}

Grigorios Vasilopoulos ( $\nabla$ g.vasilopoulos@hull.ac.uk)

University of Hull https://orcid.org/0000-0003-1519-3442

\section{Quan Quan}

University of Hull

Daniel Parsons

University of Hull https://orcid.org/0000-0002-5142-4466

\section{Stephen Darby}

University of Southampton

\section{Van Tri}

Can Tho University

Nguyen Hung

Southern Institute of Water Resources Research

Ivan Haigh

University of Southampton

Hal Voepel

University of Southampton

Andrew Nicholas

University of Exeter

Rolf Aalto

University of Exeter

\section{Article}

Keywords: Hydrodynamic Modelling, Tidal Extension, Channel Deepening

Posted Date: October 6th, 2020

DOI: https://doi.org/10.21203/rs.3.rs-81555/v1

License: (9) This work is licensed under a Creative Commons Attribution 4.0 International License. Read Full License 


\section{Anthropogenic sediment starvation forces tidal dominance in a mega-delta}

3 G. Vasilopoulos $^{1 *}$, Q.L. Quan ${ }^{1,2}$, D.R. Parsons ${ }^{1}$, S.E. Darby ${ }^{3}$, V.P.D. Tri ${ }^{4}$, N.N. Hung ${ }^{2}$, I.D.

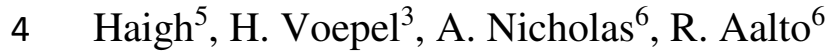

5

$6 \quad{ }^{1}$ Energy and Environment Institute, University of Hull, Hull, UK

$7 \quad{ }^{2}$ Southern Institute of Water Resources Research, Ho Chi Minh City, Vietnam

$8{ }^{3}$ School of Geography and Environmental Sciences, University of Southampton,

9 Southampton, UK

$10{ }^{4}$ College of Environment and Natural Resources, Can Tho University, Can Tho, Vietnam

$11{ }^{5}$ Ocean and Earth Science, University of Southampton, National Oceanography Centre

12 Southampton, Southampton, UK

$13 \quad{ }^{6}$ College of Life and Environmental Sciences, University of Exeter, Exeter, UK

15 *email: g.vasilopoulos@ hull.ac.uk 
The world's major river deltas provide bountiful ecosystem services to hundreds of millions of people ${ }^{1,2}$, but there are widespread concerns that their ability to support these critical functions is being threatened by increases in salinity and the extent of tidal zones $^{3}$, forced by sea-level rise ${ }^{4}$. Changes in the position of the fluvial-marine interface are governed not only by climate-driven sea-level rise, but by other factors including variations in river discharge and channel geometry ${ }^{5,6}$. However, the relative contributions of different driving factors to shifting tidal extent remains unconstrained. Here we use new field data and hydrodynamic modelling to quantify the influence of these different driving factors on accelerating tidal extension in the Mekong delta, both for the recent past and projected into the future under a range of policy, regulation and climate change scenarios. Our results indicate that, within the next two decades, tidal extension into the delta will increase by up to $56 \mathrm{~km}$ due to channel deepening, primarily driven by anthropogenic sediment starvation, which accounts for almost all (92\%) of this incursion. Eustatically rising sea-levels are found to contribute only modestly. These findings will be transferable to other large sediment starved deltas that are facing similar challenges.

The world's deltas occupy less than $1 \%$ of the global land surface, but 339 million people (4.5\% of the global population) live on them ${ }^{7}$. The ecosystem services that deltas support provide a range of socio-economic functions ${ }^{2}$ that underpin global food security ${ }^{4}$. However, many large deltas are being drowned ${ }^{1}$ due to rapid relative sea-level rise, which in 46 of the world's largest deltas averages rates of $>6 \mathrm{~mm} \mathrm{yr}^{-1(8)}$, presenting a major threat to these systems ${ }^{9}$. The rapid rises in relative sea-levels that are affecting large deltas stem from a range of compound pressures including eustatic sea-level rise, accelerated subsidence and sediment starvation ${ }^{10-12}$. Some studies estimate that by 2100 , greenhouse gas (GHG)-driven 
eustatic sea-level rise alone will increase the areas at risk of flooding in the world's deltas by $>50 \%{ }^{1}$, exacerbating saline intrusion into their sensitive ecosystems ${ }^{3,4}$. Delta subsidence, driven by compaction of sedimentary strata ${ }^{13}$, is also being accelerated due to increased rates of ground water extraction ${ }^{14,15}$. Furthermore, many large deltas are also sediment starved ${ }^{16}$ due to major reductions in the supply of fluvial sediment caused by upstream dam construction $^{17,18}$, rapid and accelerating sand mining ${ }^{19,20}$, and the construction of flood embankments $^{12,21,22}$. Such sediment starvation potentially compromises the ability of deltas to offset rising sea-levels through sediment deposition ${ }^{1,23}$. The combined influence of these compounded pressures of relative sea-level rise and changes in water and sediment discharges, driven by global warming ${ }^{24}$ and catchment engineering ${ }^{25}$, directly effects the sensitive balance between fluvial and tidal forces that governs tidal extent in large deltas. This is important because the tidal extent regulates saline intrusion ${ }^{26}$, water and sediment routing ${ }^{27}$, and channel stability ${ }^{28}$. Yet, the relative impacts of the distinct pressures influencing tidal extent have not been quantified, hampering evidence-based policy to underpin adaptation and mitigation strategies.

Here we use numerical hydrodynamic modelling to develop the first analysis of the respective influence of eustatic sea-level rise, river discharge and delta channel changes, the latter partitioned into channel erosion and subsidence, on tidal extension in a major delta, both for the recent past (1998-2018) and into the future (to 2098). We focus on the Mekong delta because it is classified by the Intergovernmental Panel on Climate Change (IPCC) as one of the three most vulnerable deltas globally ${ }^{29}$ and because it is representative of other large deltas in terms not only of the multiple drivers of change it is experiencing, but also in its response to these compound pressures. For example, similar to many other large deltas ${ }^{16}$, the supply of fluvial sediment to the Mekong has in recent decades been experiencing a major

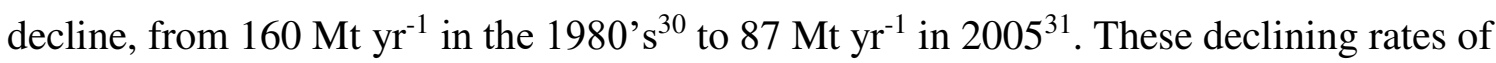


fluvial sediment supply have been attributed to the effects of shifting tropical cyclonic tracks $^{31}$ as well as extensive river impoundment and hydropower development across the Mekong's catchment ${ }^{18}$. Furthermore, sections of the river and its delta have been subject to intensive sand mining, some of which is not regulated ${ }^{32}$, with official statistics alone

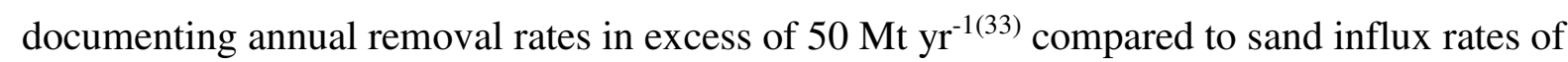

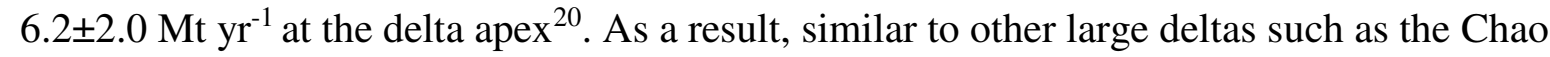
Phraya $^{34,35}$, Pearl $^{36}$, Yangtze ${ }^{37}$ and Yellow ${ }^{38}$, the Mekong is subject to severe, anthropogenically-driven, sediment starvation, resulting in rapid and extensive channel erosion $^{39}$. Synchronous to this channel erosion, the delta is also experiencing: (i) a eustatic rising of sea-levels, forced by global warming, which for the Mekong delta region is projected to be up to $1 \mathrm{~m}$ by 2100 (RCP 8.5) (relative to 1998) (see Methods and Extended Data Fig. 8), and; (ii) an anthropogenically accelerated sediment compaction which is projected to give cumulative subsidence of up to $1.4 \mathrm{~m}$ by 2100 (relative to 1990), under the most extreme ground water extraction scenario ${ }^{40}$.

\section{Anthropogenic channel bed-level lowering}

To develop our hydrodynamic simulations of the Mekong delta, we used extensive field survey data (collected in 2018, see Methods) to map the topography of the Vietnamese Mekong delta's (henceforth VMD) principal distributary channel network (Fig. 1a). We also collated historical channel surveys ${ }^{41}$, albeit covering only around $51 \%$ of the principal channel network, for the years 1998 and 2008. We then compared (see Methods) the common areas of the historical $(1998,2008)$ and contemporary (2018) channel surveys to reveal a substantial, accelerating, bed-level lowering of the delta channels since 1998. Specifically, our data reveal a mean bed-level lowering of $2.5 \mathrm{~m}(\sigma=3.9 \mathrm{~m})$ since 1998 , with change being most prominent in the landward sections, whereas in areas very close to the shore 
almost no change was observed (Fig. 1a). Comparisons at decadal intervals reveal that the bed levels of the common areas were lowered by $0.9 \mathrm{~m}(\sigma=3.2 \mathrm{~m})$ during 1998-2008, and by $1.6 \mathrm{~m}(\sigma=2.9 \mathrm{~m})$ during 2008-2018 (Extended Data Fig. 2). Volumetric differencing of the common areas, and removal of the relatively small influence of subsidence from measured changes (see later and Methods), for the 1998, 2008 and 2018 surveys, revealed historical sediment losses of 55 $\pm 17 \mathrm{Mt} \mathrm{yr}^{-1}$ during 1998-2008 and 94 $\pm 20 \mathrm{Mt} \mathrm{yr}^{-1}$ during 2008-2018. Extrapolating these values of channel erosion over the full extent of the VMD principal channel network gave estimated total sediment losses of $108 \pm 33 \mathrm{Mt} \mathrm{yr}^{-1}$ and $184 \pm 39{\mathrm{Mt} \mathrm{yr}^{-1}}^{-1}$ for 1998-2008 and 2008-2018, respectively (Fig. 1b). We then combined the observed trajectory of bed-level lowering with the 2018 survey, which covered the entire principal channel network, taking into consideration the spatial variability of quantified changes (see Methods and Extended Data Figs. 3, 4). This enabled us to project the future morphology of the delta channels (Fig. 1c), assuming a 'business as usual' evolution of compound pressures, giving an estimated bed-level lowering of some 5.3 (3.9) $\mathrm{m}$ by 2038 (2028), relative to the 1998 analogue.

The average GHG-driven eustatic sea-level rise is projected as $0.25 \mathrm{~m}$ in 2038 , relative to 1998 regional sea levels (Fig. 1d, blue line), across all Representative Concentration Pathway (RCP) scenarios we consider here ${ }^{42}$ (Extended Data Fig. 8). In contrast, the linearly projected channel geometry for 2038, forced by sediment starvation and subsidence, is some $5.3 \mathrm{~m}$ lower than in 1998 (Fig. 1d, red line) suggesting that the channel bottoms in 2038 will be some $5.55 \mathrm{~m}$ lower with respect to sea-level than they were in 1998 (Fig. 1d, black line). Estimates of historical and future subsidence for the VMD indicate only $\sim 0.2 \mathrm{~m}$ of cumulative subsidence during 1991-2018, which is projected to increase to $0.4 \mathrm{~m}$ by 2038 , under a worst-case scenario of groundwater abstraction ${ }^{40}$ (Fig. 1d, green line). Therefore, the vast majority of bed-level lowering in our scenarios for the recent past ( 2.3 of $2.5 \mathrm{~m}$ between 
117 erosion (Fig. 1d, orange line) triggered by anthropogenic sediment starvation under the

118 combined influence of reduced sediment supply from the catchment and excessive river bed 119 mining.

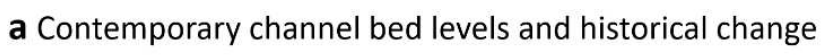

C Projected channel bed levels
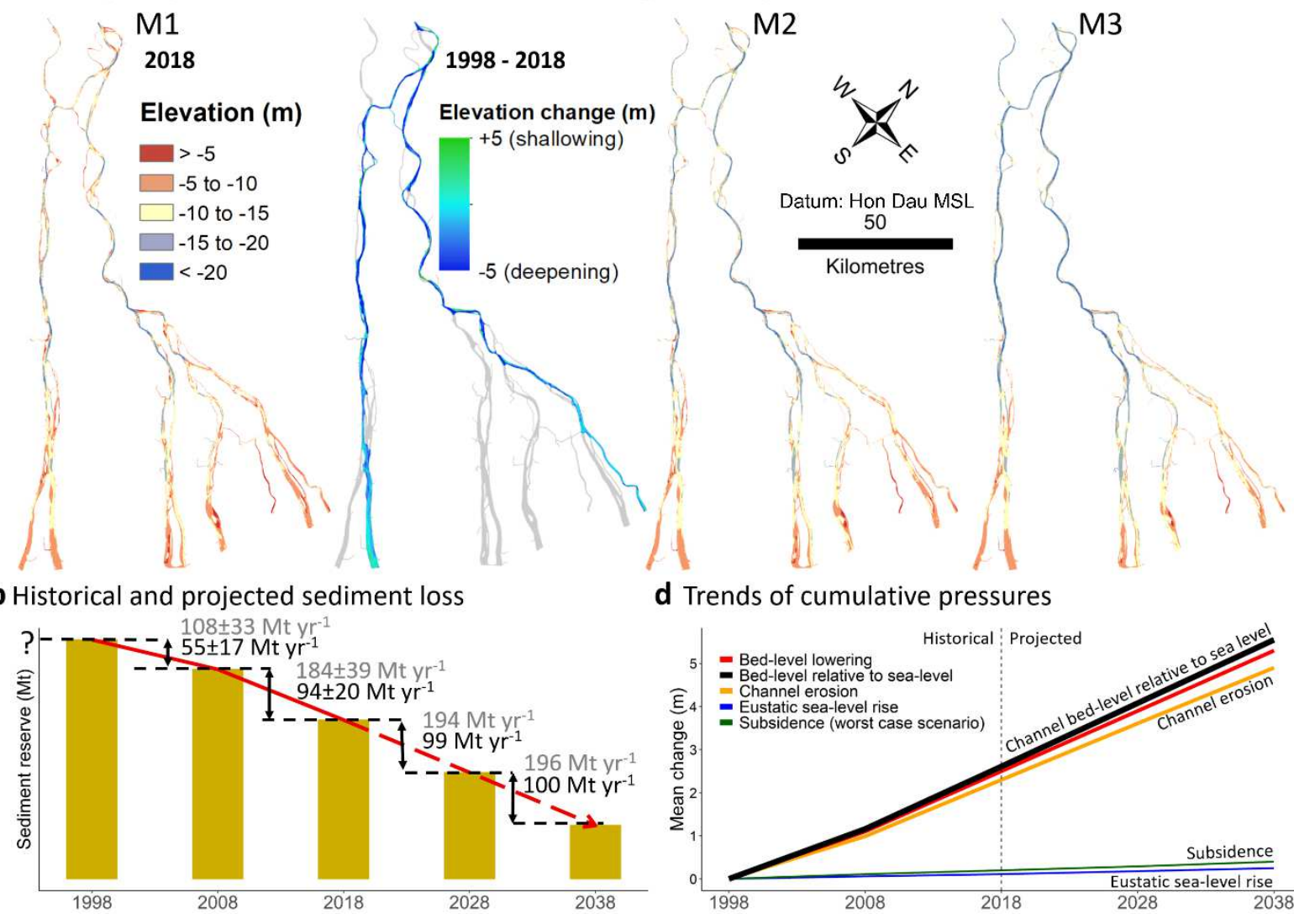

d Trends of cumulative pressures

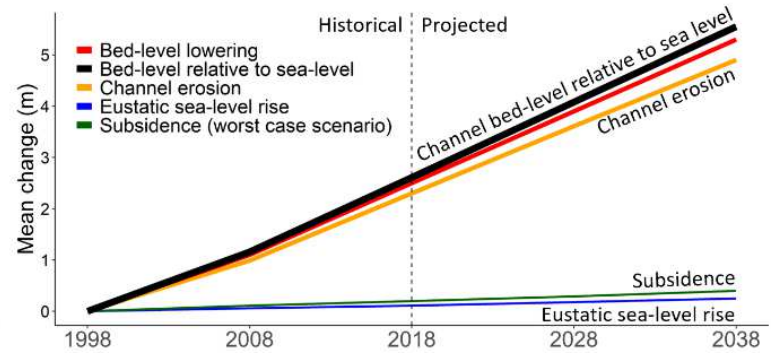

121 Fig. 1| Evolution trajectories for the Vietnamese Mekong delta. a, Contemporary (2018) bed elevations of the principal delta channel network also showing bed-level changes relative to 1998 (missing areas in grey). b, Sediment losses computed for the historical (1998-2018) period (extrapolated to the full delta extent in grey) and linearly extrapolated 20 years into the future. c, Future delta morphologies generated via linear projected estimates of future channel evolution. d, Trend of channel bed-level relative to sea-level broken down into eustatic sea-

127 level rise and channel bed lowering components, the latter being the sum of channel erosion and subsidence ${ }^{40}$. 
All our hydrodynamic modelling (see Methods) was forced by a progressive bed-level lowering of the delta distributary channels. Specifically, we constructed two historical analogue scenarios to represent the 1998 (HA1) and 2008 (HA2) bathymetries and three potential sediment management mitigation scenarios (see Methods). The first mitigation scenario (Scenario M1) is a hypothetical scenario in which effective regulation is enforced immediately to maintain the delta channel geometry at its contemporary (i.e., 2018) state (Fig.1a). Scenario M2 corresponds to a trajectory where mitigation is deferred and the delta channels continue to lower their beds at their present rates until 2028, when further bed-level lowering is halted by policy intervention. Scenario M3 represents a trajectory in which mitigation is delayed until 2038 (Fig.1c). The hydrodynamic modelling was also forced by a eustatic sea-level rise (Fig. 1d) corresponding to the regional RCP projections (see Methods and Extended Data Fig. 8) and with river discharges corresponding to the 2001, 2010 and 2013 annual hydrographs to simulate a wet, dry and median monsoonal year, respectively (see Methods and Extended Data Fig. 8). These river discharges cover a range spanning more than one standard deviation around the 2001-2018 mean annual flow (Extended Data Fig. 8). A total of 105 scenarios were investigated (90 are shown in Fig. 2), spanning a wide range of compound pressures. Simulated discharges (see Methods) show strong seasonal variability, driven by the monsoon-governed variations in river discharge, as well as hourly fluctuations governed by the tidal oscillations of the sea boundary. We quantify the tidal extent for each scenario by measuring the mean distance between the tidal limit (see Methods for definition) and the channel mouths $(n=7)$. Henceforth we report values of tidal extent corresponding to the median (2013) river discharge, values for the lower (2001; wet year) and upper (2010; dry year) bounds are provided in Fig. 2. 
The simulated average tidal extent (TE) into the delta in 1998 was $41 \mathrm{~km}$. Our simulations

show that if the channel geometry had been maintained at 1998 conditions (HA1), the tidal limit would have migrated only $1.3 \mathrm{~km}$ landward $(\mathrm{TE}=42.3 \mathrm{~km})$ during 1998-2018 and an additional $9.3 \mathrm{~km}(\mathrm{TE}=51.6 \mathrm{~km})$ during 2018-2098, driven solely by the eustatically rising sea-levels (Fig. 2, grey panels) predicted by the RCPs (see Methods). However, for the simulations in which the bed-level lowering during 1998-2018 is included, migration of the tidal limit was forced landward by $13.2 \mathrm{~km}$ so that its predicted location by 2018 was 54.2 $\mathrm{km}$ from the channel mouths. Should immediate (2018) aggressive action be taken to halt channel deepening (Scenario M1), the tidal limit is predicted to migrate a further $7.1 \mathrm{~km}$ landward $(\mathrm{TE}=61.3 \mathrm{~km}$ ) by 2098 due to the ongoing eustatic sea-level rise (Fig. 2, green panels). In the M1 scenario, the tidal limit $(\mathrm{TE}=61.3 \mathrm{~km})$ predicted in 2098 is located almost $10 \mathrm{~km}$ further landward than the HA1-based equivalent $(\mathrm{TE}=51.6 \mathrm{~km})$. However, if channel degradation continues for another decade (scenario M2), the predicted tidal extent by 2098 is $89.9 \mathrm{~km}$, some $35.7 \mathrm{~km}$ more than in 2018 (Fig. 2, orange panels). And, if channel degradation is not halted until 2038 (scenario M3) tidal extent is predicted to more than double by $2098(\mathrm{TE}=106.3 \mathrm{~km})$, an increase of $52 \mathrm{~km}$ relative to 2018 (Fig. 2, red panels).

These trajectories, showing the potential future evolution of the tidal extent within the delta system under different drivers of change, are summarised in Fig. 3. The VMD is subjected to two groups of pressures of different magnitude. GHG-driven sea-level rise alone forces a slow, progressive, tidal extension of $\sim 0.1 \mathrm{~km} \mathrm{yr}^{-1}$ (Fig. 3, grey dotted line). However, channel bed-level lowering, dominated by erosion during the last twenty years, forces a much more rapid $\left(0.5 \mathrm{~km} \mathrm{yr}^{-1}\right)$ landward migration of the tidal limit (Fig. 3, black line). If the process of bed-level lowering continues unmitigated, the tidal extent in 2098 is projected to be double that in 2018. Our simulations also show abrupt accelerations of the landward migration of the tidal limit, interpreted here as being related to the location of the tidal limit relative to the 
178 delta topology. Since the delta is increasingly bifurcated downstream ${ }^{43}$, and because channel 179 widths increase seaward where tides are more dominant ${ }^{27}$, both the number of distributary 180 channels and the total channel cross-sectional area decrease landward (Extended Data Fig. 181 10). Thus, as the tidal limit migrates landward, fewer and narrower channels exist to attenuate 182 tidal energy. This mechanism creates a positive feedback which propagates the tidal limit further landward. Considering our historical trajectory (Fig. 3, black line) in relation to the delta topology (Extended Data Fig. 10) suggests that channel narrowing further exacerbated the tidal extension (which is driven primarily by channel erosion) between 2008 (TE $=44.5$ $\mathrm{km})$ and $2018(\mathrm{TE}=54.2 \mathrm{~km})$. Our future trajectories will also similarly accelerate should the 187 tidal extent become greater than $70 \mathrm{~km}$, which falls within a transition zone $(60-90 \mathrm{~km})$ of acute reduction of total cross-sectional area and number of distributary channels (Extended Data Fig. 10). This key distance of $70 \mathrm{~km}$ is also close to the major cities of Can Tho (c. 75 $\mathrm{km}$ ) and Vinh Long (c. $80 \mathrm{~km}$ ) and could be crossed by the tidal incursion in the near (before 2038) or medium-term (after 2064) future under scenarios M3 and M2, respectively. If 192 immediate action to halt channel deepening is taken (scenario M1) the tidal extent will remain relatively constrained $(\mathrm{TE}<70 \mathrm{~km})$, for the majority of fresh-water fluxes, until the end of the century, avoiding this risk. 


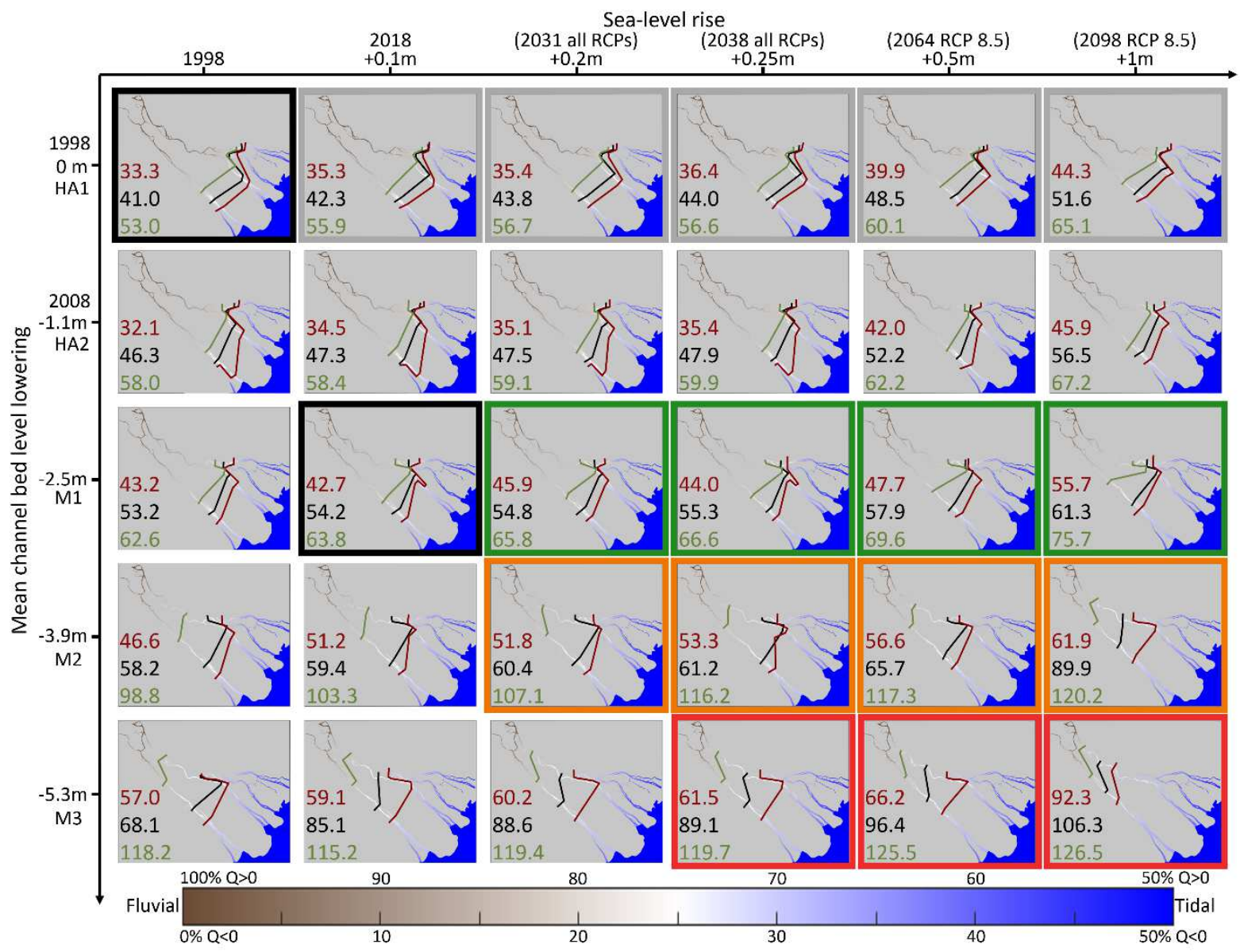

196 Fig. 2| Simulated mean annual tidal extent. The colour scale indicates the fluvial-tidal

197 transition (under a median annual river discharge). Green, black and red lines show the

198 location of the tidal limit under low, median and high mean annual river discharges,

199 respectively. Text labels indicate the tidal extent for each scenario. Sea-level rise is denoted

200 on the horizontal axis and is relative to local mean sea-level for 1998 (see Methods). Mean

201 channel bed lowering scenarios M1, M2 and M3 (see Methods) are denoted along the vertical

202 axis relative to the 1998 (HA1) channel morphology. Coloured borders relate to the trajectories of Fig. 3. 


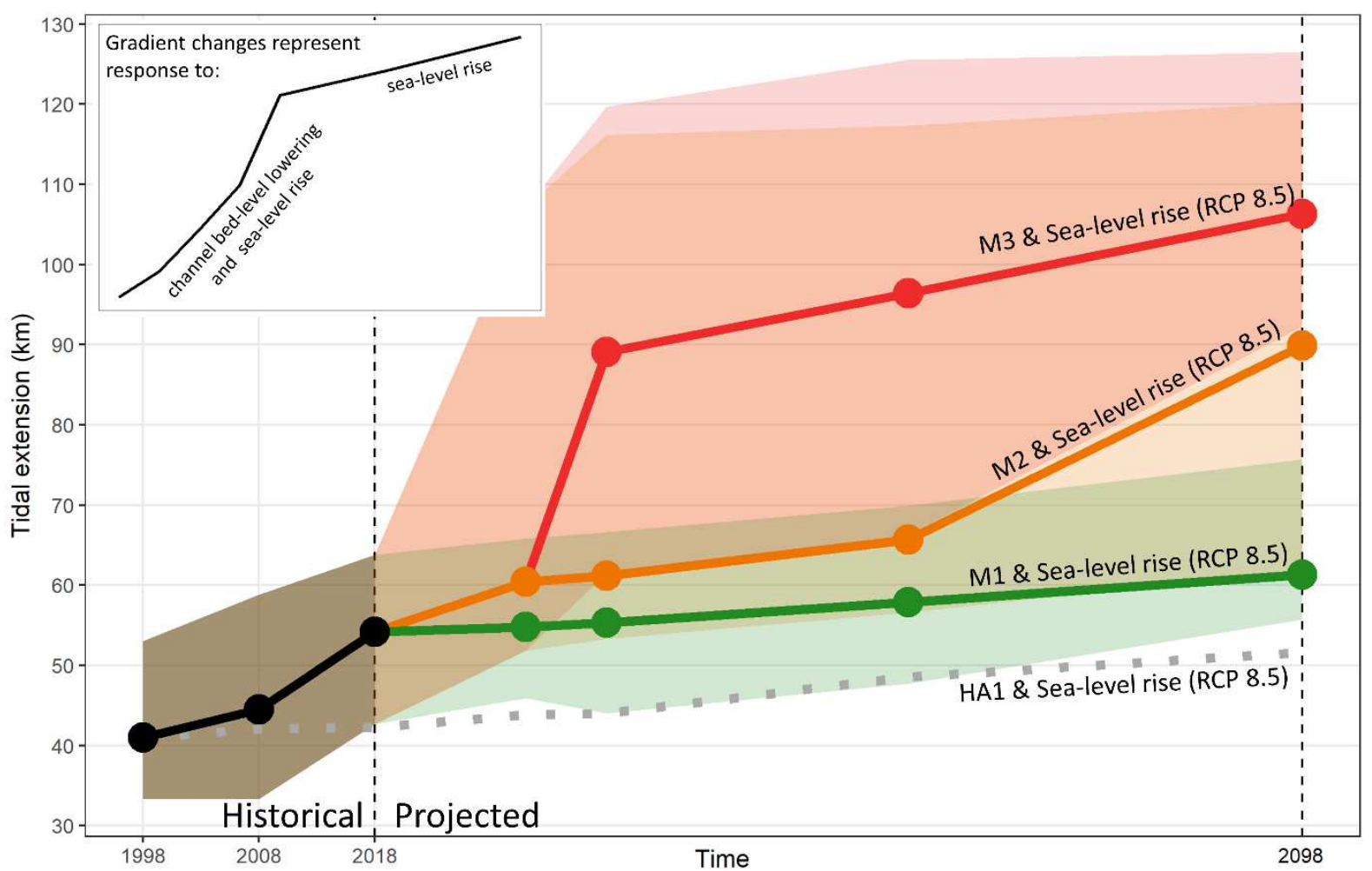

Fig. 3 | Future trajectories of tidal extension under the mitigation scenarios M1, M2 and M3.

The black line denotes the historical trend, the grey dotted line represents a hypothetical trend (HA1) forced only by rising sea-levels with no channel change relative to 1998 . Coloured lines show projected future tidal extension driven by combinations of channel bed-level lowering and rising sea-levels under the M1 (green), M2 (orange) and M3 (red) mitigation scenarios. Lines and coloured ribbons represent the median, lower and upper bounds of mean annual river discharge scenarios, respectively. Coloured circles correspond to the tidal extents indicated in Fig. 2.

\section{Discussion}

Should channel bed lowering continue unmitigated, tidal extent in the Mekong delta will increase by $\sim 56 \mathrm{~km}$ in the next two decades. This dramatic landward migration of the tidal

217 limit risks causing a collapse of ecosystem services, threatening food security, via exacerbation of saline intrusion ${ }^{4,26}$. Tidal extension also affects delta channel stability and 
219 flood risk because of changes in bifurcation function ${ }^{28}$ and water and sediment routing ${ }^{27}$. It is imperative, therefore, to identify correctly the dominant drivers of tidal extension in order to develop viable mitigation and adaptation strategies. Importantly, to date the dominant

222 narrative has focused on the role of climate change driven sea-level rise $\mathrm{e}^{3,4}$ and land subsidence ${ }^{15,40}$ in driving tidal extension. Our results highlight that although such factors are indeed important contributors to tidal extension in the long term (i.e., by 2100), channel erosion linked to anthropogenic sediment starvation, induced not only by damming but also sand mining, has a rapid and substantial influence that dominates all other drivers of tidal extension combined. This means that attempts to mitigate against tidal extension must focus on reversing the negative sediment budgets that are driving channel erosion. Our findings likely have widespread implications, as the Mekong is not the only large delta system that is sediment starved and which is highly vulnerable to tidal extension. Fluvial sediment reduction has been reported for many large rivers ${ }^{16}$ and their deltas including the Chao

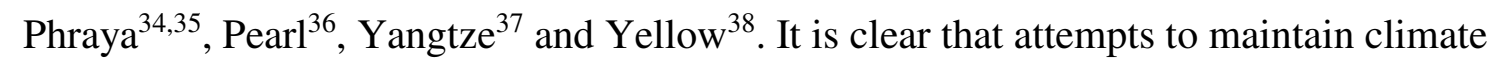
resilient deltas globally will fail unless they include efforts to establish, sustain and enhance positive sediment budgets into their fragile systems.

1. Syvitski, J. P. M. et al. Sinking deltas due to human activities. Nat. Geosci. 2, 681-686 (2009).

2. Szabo, S. et al. Population dynamics, delta vulnerability and environmental change: comparison of the Mekong, Ganges-Brahmaputra and Amazon delta regions. Sustain. Sci. 11, 539-554 (2016).

3. Ensign, S. H. \& Noe, G. B. Tidal extension and sea-level rise: recommendations for a research agenda. Front. Ecol. Environ. 16, 37-43 (2018).

4. Smajgl, A. et al. Responding to rising sea levels in the Mekong Delta. Nat. Clim. 
5. Cai, H., Savenije, H. H. G., Yang, Q., Ou, S. \& Lei, Y. Influence of river discharge and dredging on tidal wave propagation: Modaomen estuary case. J. Hydraul. Eng. 138, 885-896 (2012).

6. Cai, H., Savenije, H. H. G. \& Toffolon, M. A new analytical framework for assessing the effect of sea-level rise and dredging on tidal damping in estuaries. J. Geophys. Res. Ocean. 117, 1-20 (2012).

7. Edmonds, D. Coastal flooding will disproportionately impact people on river deltas.

9. Anthony, E. J. et al. Linking rapid erosion of the Mekong River delta to human activities. Sci. Rep. 5, 1-12 (2015).

10. Ericson, J. P., Vörösmarty, C. J., Dingman, S. L., Ward, L. G. \& Meybeck, M. Effective sea-level rise and deltas: Causes of change and human dimension implications. Glob. Planet. Change 50, 63-82 (2006).

11. Syvitski, J. P. M. Deltas at risk. Sustain. Sci. 3, 23-32 (2008).

12. Vörösmarty, C. J. et al. Battling to save the world's river deltas. Bull. At. Sci. 65, 3143 (2009).

13. Törnqvist, T. E. et al. Mississippi Delta subsidence primarily caused by compaction of Holocene strata. Nat. Geosci. 1, 173-176 (2008).

14. Zhang, Y. et al. Land subsidence and earth fissures due to groundwater withdrawal in the Southern Yangtse Delta, China. Environ. Geol. 55, 751 (2007). 
subsidence, and sea-level rise in the Mekong Delta, Vietnam. Environ. Res. Lett. 9, (2014).

16. Dunn, F. E. et al. Projections of declining fluvial sediment delivery to major deltas worldwide in response to climate change and anthropogenic stress. Environ. Res. Lett. 14, 84034 (2019).

17. Dai, Z. \& Liu, J. T. Impacts of large dams on downstream fluvial sedimentation: An example of the Three Gorges Dam (TGD) on the Changjiang (Yangtze River). $J$. Hydrol. 480, 10-18 (2013).

18. Kondolf, G. M., Rubin, Z. K. \& Minear, J. T. Dams on the Mekong: Cumulative sediment starvation. Water Resour. Res. 50, 5158-5169 (2014).

19. Bravard, J.-P., Goichot, M. \& Tronchère, H. An assessment of sediment-transport processes in the Lower Mekong River based on deposit grain sizes, the CM technique and flow-energy data. Geomorphology 207, 174-189 (2014).

20. Hackney, C. R. et al. River bank instability from unsustainable sand mining in the lower Mekong River. Nat. Sustain. (2020).

21. Auerbach, L. W. et al. Flood risk of natural and embanked landscapes on the GangesBrahmaputra tidal delta plain. Nat. Clim. Chang. 5, 153-157 (2015).

22. Chapman, A. et al. Sustainable rice cultivation in the deep flooded zones of the Vietnamese Mekong Delta. Vietnamese Sci. Technol. 59, 34-38 (2017).

23. Giosan, L., Syvitski, J., Constantinescu, S. \& Day, J. Climate change: protect the world's deltas. Nat. News 516, 31 (2014).

24. Lan, C. W., Lo, M. H., Chou, C. \& Kumar, S. Terrestrial water flux responses to global warming in tropical rainforest areas. Earth's Futur. 4, 210-224 (2016).

25. Vörösmarty, C. J. \& Sahagian, D. Anthropogenic Disturbance of the Terrestrial Water Cycle. Bioscience 50, 753 (2000). 
26. Eslami, S. et al. Tidal amplification and salt intrusion in the Mekong Delta driven by anthropogenic sediment starvation. Sci. Rep. 9, 1-10 (2019).

27. Nienhuis, J. H., Hoitink, A. J. F. T. \& Törnqvist, T. E. Future Change to TideInfluenced Deltas. Geophys. Res. Lett. 45, 3499-3507 (2018).

28. Zhang, W. et al. Tidal impacts on the subtidal flow division at the main bifurcation in the Yangtze River Delta. Estuar. Coast. Shelf Sci. 196, 301-314 (2017).

29. Parry, M. et al. Cross-chapter case study. in Climate change 2007-impacts, adaptation and vulnerability: Working group II contribution to the fourth assessment report of the IPCC vol. 4 858-861 (Cambridge University Press, 2007).

30. Milliman, J. D. \& Meade, R. H. World-wide delivery of river sediment to the oceans. J. Geol. 91, 1-21 (1983).

31. Darby, S. E. et al. Fluvial sediment supply to a mega-delta reduced by shifting tropical-cyclone activity. Nature 539, 276-279 (2016).

32. Jordan, C. et al. Sand mining in the Mekong Delta revisited - current scales of local sediment deficits. Sci. Rep. 9, 1-14 (2019).

33. Bravard, J.-P., Goichot, M. \& Gaillot, S. Geography of sand and gravel mining in the Lower Mekong River. First survey and impact assessment. EchoGéo (2013).

34. Saito, Y., Thanawat, J. \& Syvitski, J. P. M. Shrinking Megadeltas in Asia: Sea-level Rise and Sediment Reduction Impacts from Case Study of the Chao Phraya Delta. Inprint Newsl. IGBP/IHDP L. Ocean Interact. Coast. Zo. 3-9 (2007).

35. Winterwerp, J. C., Borst, W. G. \& De Vries, M. B. Pilot study on the erosion and rehabilitation of a mangrove mud coast. J. Coast. Res. 21, 223-230 (2005).

36. Zhang, S. et al. Recent changes of water discharge and sediment load in the Zhujiang (Pearl River) Basin, China. Glob. Planet. Change 60, 365-380 (2008).

37. Yang, S. L., Xu, K. H., Milliman, J. D., Yang, H. F. \& Wu, C. S. Decline of Yangtze 
River water and sediment discharge: Impact from natural and anthropogenic changes. Sci. Rep. 5, 1-14 (2015).

38. Wang, H. et al. Recent changes in sediment delivery by the Huanghe (Yellow River) to the sea: causes and environmental implications in its estuary. J. Hydrol. 391, 302313 (2010).

39. Brunier, G., Anthony, E. J., Goichot, M., Provansal, M. \& Dussouillez, P. Recent morphological changes in the Mekong and Bassac river channels, Mekong delta: The marked impact of river-bed mining and implications for delta destabilisation. Geomorphology 224, 177-191 (2014).

40. Minderhoud, P. S. J., Middelkoop, H., Erkens, G. \& Stouthamer, E. Groundwater extraction may drown mega-delta: projections of extraction-induced subsidence and elevation of the Mekong delta for the 21st century. Environ. Res. Commun. 2, 011005 (2020).

41. Mekong River Commission. Mekong River Commission. http://www.mrcmekong.org/.

42. Goodwin, P., Haigh, I. D., Rohling, E. J. \& Slangen, A. A new approach to projecting 21st century sea-level changes and extremes. Earth's Futur. 5, 240-253 (2017).

43. Edmonds, D. A. \& Slingerland, R. L. Stability of delta distributary networks and their bifurcations. Water Resour. Res. 44, 1-13 (2008). 


\section{Methods}

338 We quantify historical bed level lowering of the principal distributary channels of the

Vietnamese Mekong delta (VMD) by comparing successive bathymetric surveys for the years 1998, 2008 and 2018. We then propagate the identified trends of bed level change 20 years forward by assuming a 'business as usual' evolution of pressures, and also generate potential future alternate delta analogues. We also develop a two-dimensional hydrodynamic numerical model (based on the delta topographies) and undertake a series of numerical experiments ( $\mathrm{n}=105$ simulation scenarios) to explore the response of delta hydraulics under a range of compound pressures, accounting for co-variations in: (1) eustatic sea-level rise; (2) river discharge, and; (3) channel bed lowering. We analyse annual time series of predicted hourly water discharges at 100 locations across the delta channel network and quantify tidal extension for each one of the scenarios investigated.

\section{Historical bathymetric surveys}

Our historical bathymetric data consist of point surveys for the years 1998 and 2008, obtained from the Mekong River Commission ${ }^{41}$. These bathymetric surveys cover approximately $51 \%$ $\left(432 \mathrm{~km}^{2}\right)$ of the delta's principal distributary channels (Extended Data Fig. 1) and have a mean survey density of 31 and 46 points $\mathrm{km}^{-2}$ for the 1998 and 2008 surveys, respectively. The datasets contain elevation values (in m), relative to the Ha Tien 1960 mean sea level (MSL) and longitude-latitude coordinate pairs (in decimal degrees) referenced to the World Geodetic System 1984 (WGS84). These datasets have been previously reported ${ }^{39}$ and are based on depth measurements obtained using a bi-frequency echosounder with a depth uncertainty of $\pm 0.2 \mathrm{~m}$ for every $10 \mathrm{~m}$ which generates a mean vertical error of 0.19 and 0.21 m for 1998 and 2008, respectively. Details about the horizontal accuracy of the survey data and precise survey dates are not specified, but are estimated to be $\pm 10 \mathrm{~m}$. We adopted the 
Universal Transverse Mercator (UTM) coordinate system and projected the geographic coordinates into WGS84 UTM 48N. We verified historic MRC data and procedures used for vertical referencing, and then converted the elevation values from the Ha Tien 1960 to the Hon Dau 1992 MSL by subtracting the 0.167 m offset from each reported elevation. Hon Dau is the vertical datum which is currently used in Viet Nam.

\section{Contemporary bathymetric survey}

Our contemporary bathymetry was obtained from a delta-wide survey we conducted in May 2018. We used two survey vessels, equipped with identical single beam echo-sounding (SBES) systems consisting of a Garmin GT20-TM sonar transducer linked to a Garmin global positioning system (GPS). The sonar transducer was mounted on a vertical pole on the side of the boats, with the transducer heads fully submerged $(\sim 0.5 \mathrm{~m})$ below the surface of the water. The precise level of submergence was checked regularly (> 1/day). For the majority of our surveys the sonars were operated at a pulse frequency of $800 \mathrm{kHz}$ that had a beam angle of $1.6^{\circ}$. At a limited number of locations, where the water depth exceeded the range that the $800 \mathrm{kHz}$ pulse frequency was capable of reaching (>40 m), we switched to a lower, $455 \mathrm{kHz}$, pulse frequency that had a wider beam angle of $2.5^{\circ}$. The SBES systems recorded data at a frequency of $1 \mathrm{~Hz}$. We continuously monitored vessel speed and kept these below $20 \mathrm{~km} \mathrm{hr}^{-1}$ to minimise air entrainment and data noise. Garmin does not specify a measurement error for their SBES system, hence we adopt the same vertical uncertainty as for the historical data (i.e. $\pm 0.2 \mathrm{~m}$ for every $10 \mathrm{~m}$ ), which generates a mean vertical error of $0.25 \mathrm{~m}$ for the 2018 dataset. We henceforth propagate the mean errors of the historical and 2018 surveys into our volumetric differencing and subsequent erosion rates. A limited part of the principal delta channels $\left(145 \mathrm{~km}^{2}\right.$ out of $854 \mathrm{~km}^{2}$ ) had already been thoroughly surveyed $\left(1084 \mathrm{pts} \mathrm{km}^{-2}\right)$ in 2014 (Extended Data Fig. 1). We surveyed these areas following a straight course along the 
channels (404 pts km${ }^{-2}$ ) to identify general trends of change within the 4-year period (see later). We then concentrated our efforts to extensively survey $\left(677 \mathrm{pts}^{-2}\right)$ the remaining areas $\left(709 \mathrm{~km}^{2}\right.$ out of $\left.854 \mathrm{~km}^{2}\right)$, that had not been surveyed since 2008 , following predefined courses aimed at optimising channel coverage. In channel reaches surveyed by a single vessel the survey tracks followed oblique cross-sections crossing from bank to bank, thereby

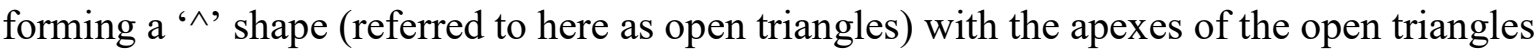
spaced approximately two channel widths apart. In channel reaches surveyed by both vessels we obtained symmetrically intertwined open triangles.

We used Sonar TRX pro ${ }^{44}$ to convert the acoustic recordings into arrays consisting of timestamps, projected (WGS84 UTM 48N) coordinates, and measurements of water depth below the transducer head. We manually removed erroneous recordings from the datasets (such erroneous recordings appeared as zero depths) and summed the water depth below the transducer to the level of submergence of the transducer head to calculate the total water depth for each data point. These total water depths were transformed to elevations using hourly water level recordings from the Vietnamese hydrological agency's network of water level monitoring stations (Extended Data Fig. 1), these water surface elevations being referenced to the Hon Dau MSL. We linearly interpolated each water surface elevation time series to provide 10-minute tide intervals. For each measurement location we then used concurrent water level recordings from cognate stations to estimate water surface elevation at the measurement location, via interpolation of the gauged water surface elevations using biharmonic splines ${ }^{45}$ in MATLAB. We then compared the bed elevations measured in 2014 with the corresponding ones measured in 2018 (following a straight course) and found that within the 4-year period the landward section of the main Mekong had been lowered by 2.9 $\mathrm{m}$ on average, whereas a limited section of the Bassac had been raised by $0.6 \mathrm{~m}$ on average. We adjusted the 2014 data accordingly and used them to augment our 2018 survey data. 


\section{Principal channel bed surfaces}

414 We used ArcGIS 10.7 to interpolate channel bed surfaces from the survey data and compare 415 historical and contemporary channel morphology. Because of flow directionality, channel topography typically varies less along the longitudinal and more along the transverse channel direction. To account for this anisotropy we employed a flow-oriented asymmetric interpolation ${ }^{46,47}$. Specifically, we used freely available Landsat images to digitise the boundary of the delta channels for the years 1998, 2008 and 2018 and partitioned them into sections of relatively constant channel direction $(n=96)$. We then selected all bathymetric data, of a specific survey, located within each section and, using the Geostatistical Analyst toolbox (Geostatistical Wizard), performed a separate ordinary kriging interpolation for each section. During each ordinary kriging interpolation, the data was detrended by identifying and removing the first order surface trend and anisotropy was accounted for by using an elliptically shaped search neighbourhood. The ellipsis was oriented with its major axis parallel to the longitudinal direction of the respective channel section, had a minor axis length similar to the mean channel width of the respective section, and an aspect ratio of approximately $3: 1$. We chose a $50 \mathrm{~m}$ cell size for the resulting interpolation surfaces. We combined the individual sections to create our contemporary and historical maps of channel bed elevations (Fig. 1 and Extended Data Fig. 2).

\section{Surface differencing and rates of historical channel erosion}

433 We converted our topographic surfaces into Triangular Irregular Networks (TINs) and used the 3D Analyst toolbox (Surface Difference) to compare historical and contemporary surfaces 
1998-2008 period the bed levels in the common areas (51\% of the principal delta channels) were lowered by an average of $0.9 \mathrm{~m}(\sigma=3.2 \mathrm{~m})$ with a calculated volumetric change of $371 \times 10^{6} \pm 105 \times 10^{6} \mathrm{~m}^{3}$ and that in the period 2008-2018 the bed levels in the common areas were lowered by an average of $1.6 \mathrm{~m}(\sigma=2.9 \mathrm{~m})$ with a calculated volumetric change of $635 \times 10^{6} \pm 122 \times 10^{6} \mathrm{~m}^{3}$. Minderhoud et al. ${ }^{40}$ have, in previous work, quantified a mean cumulative subsidence of the Mekong delta plain of $0.2 \mathrm{~m}$ for the period 1990-2018. Therefore, at least 2.3 out of the $2.5 \mathrm{~m}(92 \%)$ of bed-level lowering that we quantify for the period 1998-2018 cannot be explained by subsidence and must be as a result of channel erosion. Accounting for this modest subsidence, this generates sediment loss estimates of approximately $341 \times 10^{6} \pm 97 \times 10^{6} \mathrm{~m}^{3}$ and $584 \times 10^{6} \pm 112 \times 10^{6} \mathrm{~m}^{3}$ which, assuming a bulk density of $1600 \mathrm{~kg} \mathrm{~m}^{-3}$, corresponds to $546 \pm 155 \mathrm{Mt}$ and $934 \pm 195 \mathrm{Mt}$ for the $1998-2008$ and 2008-2018 periods, respectively. We assume that the channel erosion we quantify here, based on the common areas ( $51 \%$ of the principal delta channels), is representative of the processes occurring in the remaining (49\%) areas of the principal delta channels that are not covered by the historical surveys. Extrapolation of the above sediment losses across the entire principal channel network suggest that the delta river bed lost sediment at average rates of $108 \pm 33 \mathrm{Mt}$

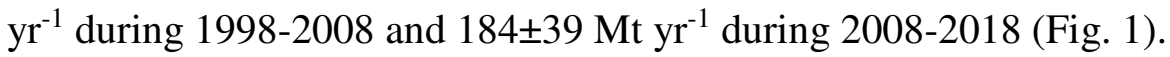

\section{Future and historical channel bed-levels}

Our channel change analyses (Extended Data Fig. 2) demonstrate that bed-level lowering has been more extensive in the landward regions of the delta, especially during 2008-2018. This is likely due to an increasing sediment influx from the coast ${ }^{48}$ and the increased sand mining activity that is particularly concentrated in the landward reaches of the VMD. To summarise this pattern, we extracted laterally averaged differences in channel topography at approximately $1 \mathrm{~km}$ intervals along the principal Mekong (section indicated as MM' in 

channels, and quantified the linear trend of change for each channel (Extended Data Fig. 3).

We then interpolated spatially the two channel change trends into raster maps that represent the historical trends of channel bed-level lowering across the principal delta channel network (Extended data Fig. 4a-b).

Due to the gaps in the historical datasets, we used the 2018 channel survey and historical trajectories to develop historical analogues of the entire delta for 1998 and 2008. Specifically, we added the 2008-2018 raster map of bed-level lowering (Extended Data Fig. 4b) to the contemporary (2018) channel survey (Fig. 1a) to produce the 2008 historical delta analogue (HA2) (Extended Data Fig. 4d). In this historical analogue (HA2) the channel bed levels of the VMD are on average higher by $1.4 \mathrm{~m}$ in 2008 , relative to the 2018 condition. We then added the 1998-2008 raster map of bed-level lowering (Extended Data Fig. 4a) to the 2008 historical delta analogue (HA2) to produce the 1998 historical delta analogue (HA1) (Extended Data Fig. 4c). In this historical analogue the channel bed levels of the VMD are on average higher by $2.6 \mathrm{~m}$, relative to the 2018 condition.

We also developed three future scenarios to represent the potential future evolution of channel geometry under different potential mitigation approaches. The first mitigation scenario (Scenario M1) is a hypothetical scenario in which effective regulation is implemented immediately to maintain the delta channel geometry at its contemporary (i.e., 2018) state and as such matches the contemporary channel bed levels (Fig. 1a). delta channels continue to lower their beds at their present rates until 2028, when further bedlevel lowering is halted. We produced the 2028 delta analogue (M2) by subtracting the 2008- 
channel survey (Fig. 1a). In this future analogue (M2) the channel bed levels of the VMD in 2028 are on average lower by 1.4 m, relative to 2018 (Fig. 1c).

Scenario M3 represents a hypothetical trajectory in which mitigation is delayed still further until 2038 when further bed-level lowering is halted. We produced the 2038 delta analogue (M3) by subtracting the 2008-2018 raster map of bed-level lowering (Extended Data Fig. 4b) from the 2028 delta analogue (M2 in Fig. 1c). In this future analogue (M3 in Fig.1c) the channel bed levels of the VMD in 2038 are on average lower by $2.8 \mathrm{~m}$, relative to 2018 . We global demand for sand.

\section{Two-dimensional (2D) hydrodynamic model}

We developed our 2D hydrodynamic model (Extended Data Fig. 5) using the Danish Hydraulics Institute's (DHI) MIKE21FM modelling suite ${ }^{49}$, using a combination of regular and flexible mesh elements $(n=244000)$. Flexible elements were used within complex sections such as channel bends and bifurcations to provide the higher levels of detail required. Regular mesh elements were used within straight channel sections to increase the model's computational efficiency. Because of its large domain and increased complexity all model simulations were undertaken using the University of Hull's High-Performance days to complete using twenty HPC nodes (560 processing cores). The domain topography was based on the 2018 measured bed elevations (M1) or the historical (HA1, HA2) or future (M2, M3) delta analogues, depending on the scenario investigated. To fully characterise the topography of the model domain we also used nearshore bathymetric data obtained in 2009 
by the Southern Institute of Water Resources Research using a Teledyne ODOM Hydrotrac echosounder coupled with a Trimble 5700 GPS. These data have a depth uncertainty of less than $10 \%$ of the measured depth. We also used offshore bathymetric data obtained from navigational charts that have a $25 \mathrm{~km}$ resolution.

The landward boundary conditions were forced by hourly time series of river discharge as measured at the Tan Chau and Chau Doc gauging stations (Extended Data Fig. 5), with each time series covering a full year of varying flow conditions. The sea boundary was forced by tidal levels at hourly intervals that also covered a full year. These tidal levels were estimated from the global ocean tide model DTU10 $0^{50}$ but calibrated against observations at three proximal monitoring stations (Gan Hao, Ben Trai and Vung Tau) (Extended Data Fig. 5), operated by the Southern Region Hydrometeorological Centre in Vietnam. To ensure the robust calibration and validation of our model, we used two distinct sets of boundary conditions corresponding to the years 2016 (for model calibration) and 2018 (for validation). The year 2018 is the year of our most recent channel survey and represents a high flood year with above-average mean annual discharge values, equal to $11767 \mathrm{~m}^{3} \mathrm{~s}^{-1}$ (mean annual flow $=$ $10140 \mathrm{~m}^{3} \mathrm{~s}^{-1}$ ) and $2553 \mathrm{~m}^{3} \mathrm{~s}^{-1}$ (mean annual flow $=2439 \mathrm{~m}^{3} \mathrm{~s}^{-1}$ ) for Tan Chau and Chau Doc, respectively. The year 2016 is close in time to our 2018 survey, but represents a dry year with below-average mean annual discharge values, equal to $8963 \mathrm{~m}^{3} \mathrm{~s}^{-1}$ and $1940 \mathrm{~m}^{3} \mathrm{~s}^{-1}$ for Tan Chau and Chau Doc, respectively. We first run simulations using the boundary conditions for 2016. Calibration was performed by adjusting the model's hydraulic roughness, running the model for a full year and comparing model predictions against observations collected at a series of monitoring stations distributed across the delta (see Extended Data Fig. 5 for locations). We calculated the Nash-Sutcliffe model efficiency coefficient ${ }^{51}$ (NSE) to assess model performance. We achieved the best calibration results (Extended Data Fig. 6) when using a roughness value with a spatially variable depth dependence. Specifically, we 
partitioned the model domain into three regions (landward, central and seaward) and defined the Manning's roughness coefficient ( $n$ ) using Equations (1)-(3):

$$
\begin{aligned}
& n_{\text {landward }}=0.0003 \times E+0.0329 \\
& n_{\text {central }}=0.0002 \times E+0.0226 \\
& n_{\text {seaward }}=0.0002 \times E+0.0201
\end{aligned}
$$

where $E$ is the local bed elevation referenced to Hon Dau MSL. The gradual reduction of the hydraulic roughness seaward, suggested by Equations (1)-(3), is in accordance to the gradual fining of the delta's bed sediments in the same direction ${ }^{52}$. We then validated our model by conducting a full year simulation run using the 2018 channel survey with 2018 boundary conditions, again computing Nash-Sutcliffe model efficiency coefficient ${ }^{51}$ (NSE) values to assess model performance (Extended Data Fig. 7).

\section{Model Scenarios}

We designed a series of 105 simulation scenarios to explore the response of delta hydraulics under a range of compound pressures, accounting for changes in: (1) eustatic sea-level rise; (2) river discharge, and; (3) channel bed-level lowering.

For eustatic sea-level rise, we used seven scenarios in our simulations, based on projections from the Warming Acidification and Sea level Projector (WASP) ${ }^{42}$, which are broadly consistent with the IPCC Fifth Assessment Report (AR5) projected range ${ }^{53}$. Specifically, we use regional projections for RCPs 2.6, 4.5, 6.0 and 8.5 for the grid point closest to the Mekong delta. Rather than using specific levels for particular RCP projections, we chose to use rounded values of sea-level rise that broadly reflect the full range projected by $\mathrm{WASP}^{42,54}$, for the grid point closest to the Mekong delta. We chose to assess $0.06,0.1,0.2$ and $0.25 \mathrm{~m}$ of sea level rise (relative to 1998) by the years 2008, 2018, 2031 and 2038, 
respectively. These levels of sea-level rise correspond approximately to average projections across all RCPs for this period (Extended Data Fig. 8). We also explored the effect of a $0.5 \mathrm{~m}$ sea-level rise which is predicted by all RCPs (but for different years) and that of a $1 \mathrm{~m} \mathrm{SLR,}$ that reflects the upper end of the RCP 8.5 by 2100 . Within the hydrodynamic model, our open sea boundary was driven by hourly tidal heights extracted from DTU10 $0^{50}$ for the full year 1998 and calibrated against hourly observations from the proximal monitoring stations of Ganh Hao, Ben Trai and Vung Tau for the same year (Extended data Fig. 8). We vertically offset the tidal height timeseries by the specific mean sea-level rise scenarios (Extended Data Fig. 8).

The effects of river discharge variability were assessed using three distinct river flow discharge data sets. Specifically, we used hourly observations of river discharge at Tan Chau and Chau Doc (see Extended Data Fig. 5 for station locations) that covered the entire years 2013, 2010 and 2001 (Extended Data Fig. 8). We selected these specific years because their mean annual discharge values are close to the median, lower and upper bounds, respectively, of the full range of discharges observed during the period 2001-2018.

Finally, to explore the effects of channel bed-level lowering on delta hydrology we repeated all simulations with five different bathymetries that included our contemporary bathymetry (M1), along with the historical (HA1, HA2) and future (M2, M3) delta analogues.

\section{Tidal Extension}

We used the 2D hydrodynamic model to simulate flow through the entire principal channel network for a full year, extracting the simulated water discharge values at one-hour intervals at 100 locations across the delta (Extended Data Fig. 9). These simulated discharges show strong seasonal variability, driven by the monsoon-governed variations in river discharge, as 
well as hourly fluctuations governed by the tidal oscillations of the sea boundary. We adopted the convention that, under complete fluvial dominance, the flow is always positive (100\% Q>0), with water flowing seaward. Under complete tidal dominance the flow would vary equally between positive and negative (inversed flow) discharge values (50\% $\mathrm{Q}>0$ ), resulting in a net zero discharge over a full year, whereas a $75 \% \mathrm{Q}>0$ represents the zone where fluvial and tidal forces equalise. At each one of the 100 study locations we used the extracted hourly discharge values across the year-long time series to calculate the ratio of positive and negative discharge. We used this ratio to map the spatial transition between fluvial and tidal dominance across the delta. Typically, the tidal limit is defined as the landward position within a delta or estuary where tidal influence is no longer evident ${ }^{55}$. For the Mekong delta, tidal-induced water level fluctuations extend into Cambodia ${ }^{56}$ further landward than our study area and model domain. We therefore adopt the location where $75 \%$ of the total annual discharge is positive to define the mean annual boundary of the tidal extent, or tidal limit (TL). In this way our defined TL is located within our study area and model domain but, more importantly, it partitions the delta into a fluvially dominated zone that extends landward of the TL and a tidally dominated zone that extends seaward.

\section{SonarTRX. SonarTRX. https://www.sonartrx.com/ (2020).}

45. Sandwell, D. T. Biharmonic spline interpolation of GEOS-3 and SEASAT altimeter data. Geophys. Res. Lett. 14, 139-142 (1987).

46. Merwade, V. M., Maidment, D. R. \& Goff, J. A. Anisotropic considerations while interpolating river channel bathymetry. J. Hydrol. 331, 731-741 (2006).

47. Legleiter, C. J. \& Kyriakidis, P. C. Spatial prediction of river channel topography by kriging. Earth Surf. Process. Landforms J. Br. Geomorphol. Res. Gr. 33, 841-867 
607

608

609

610

611

612

613

614

615

616

617

618

619

620

621

622

623

624

625

626

627

628

48. Ha, D. T., Ouillon, S. \& Van Vinh, G. Water and suspended sediment budgets in the lower mekong from high-frequency measurements (2009-2016). Water (Switzerland) 10, (2018).

49. Mikepoweredbydhi.com. MIKE Powered by DHI | Superior tools for modelling water environments. https://www.mikepoweredbydhi.com/ (2020).

50. Cheng, Y. \& Andersen, O. B. Improvement in global ocean tide model in shallow water regions. Poster, SV 1-68 (2010).

51. Nash, J. E. \& Sutcliffe, J. V. River flow forecasting through conceptual models part I-A discussion of principles. J. Hydrol. 10, 282-290 (1970).

52. Gugliotta, M., Saito, Y., Nguyen, V. L., Ta, T. K. O. \& Tamura, T. Sediment distribution and depositional processes along the fluvial to marine transition zone of the Mekong River delta, Vietnam. Sedimentology 66, 146-164 (2019).

53. Church, J. A. et al. Sea level change. Climate change 2013: the physical science basis. Contribution of working group I to the fifth assessment report of the intergovernmental panel on climate change. Cambridge Univ. Press. Cambridge, United Kingdom New York, NY, USA 1137-1216 (2013).

54. Oppenheimer, M. et al. Sea level rise and implications for low lying islands, coasts and communities. (2019).

55. Davis Jr, R. A. \& Dalrymple, R. W. Principles of tidal sedimentology. (Springer Science \& Business Media, 2011).

56. Gugliotta, M. et al. Process regime, salinity, morphological, and sedimentary trends along the fluvial to marine transition zone of the mixed-energy Mekong River delta, 
Data availability Historical $(1998,2008)$ channel survey data are available from the Mekong River Commission at: https://portal.mrcmekong.org/data-catalogue. The cotemporary (2018) channel survey data collected with the SBES, the 1998-2018 hourly time series of water discharge and the hourly time series of water surface elevations for years 2016 and 2018 are available at: https://hydra.hull.ac.uk/resources/hull:17951 . Sea level rise predictions produced by WASP are available at:

\section{https://ivanhaigh.com/data/obshist_annual_gms1_projections/.}

Acknowledgments This research was co-funded by the UK National Environmental

Technology Development (NAFOSTED) under the grant number: NE/P014704/1 and supported by the Viet Nam Ministry of Science and Technology, Project Code KC08.12/1620 "Study on adversed impact of the river bed degradation of the lower Mekong River and proposed mitigation solution". D.R.P. additionally acknowledges funding received from the European Research Council under the European Union's Horizon 2020 research and innovation program (Grant Agreement 725955). G.V. thanks V. Dung, M.V. Bao, H.P. Pham, T.M. Nhat, S. Teasdale, J. Johnson, and C. Hackney for their help during the channel survey and C. Collins for High Performance Computing support.

Author contributions G.V., D.R.P., S.E.D., Q.L.Q, V.P.D.T., N.N.H., H.V., R.A., A.N., conceived the study. G.V., S.E.D. and D.R.P. wrote the initial draft. G.V. analysed all data. G.V. and Q.L.Q. carried out the bathymetric survey. Q.L.Q. built the numerical model. I.D.H. developed the sea-level predictions for the Mekong. V.P.D.T. and N.N.H. supported the 
654 bathymetric survey. G.V, S.E.D., D.R.P, R.A. and Q.L.Q. discussed the results. All authors 655 contributed to the writing of the manuscript.

656

657 Competing interests The authors declare no competing interests

658

659 Correspondence and requests for materials should be addressed to G.V. 

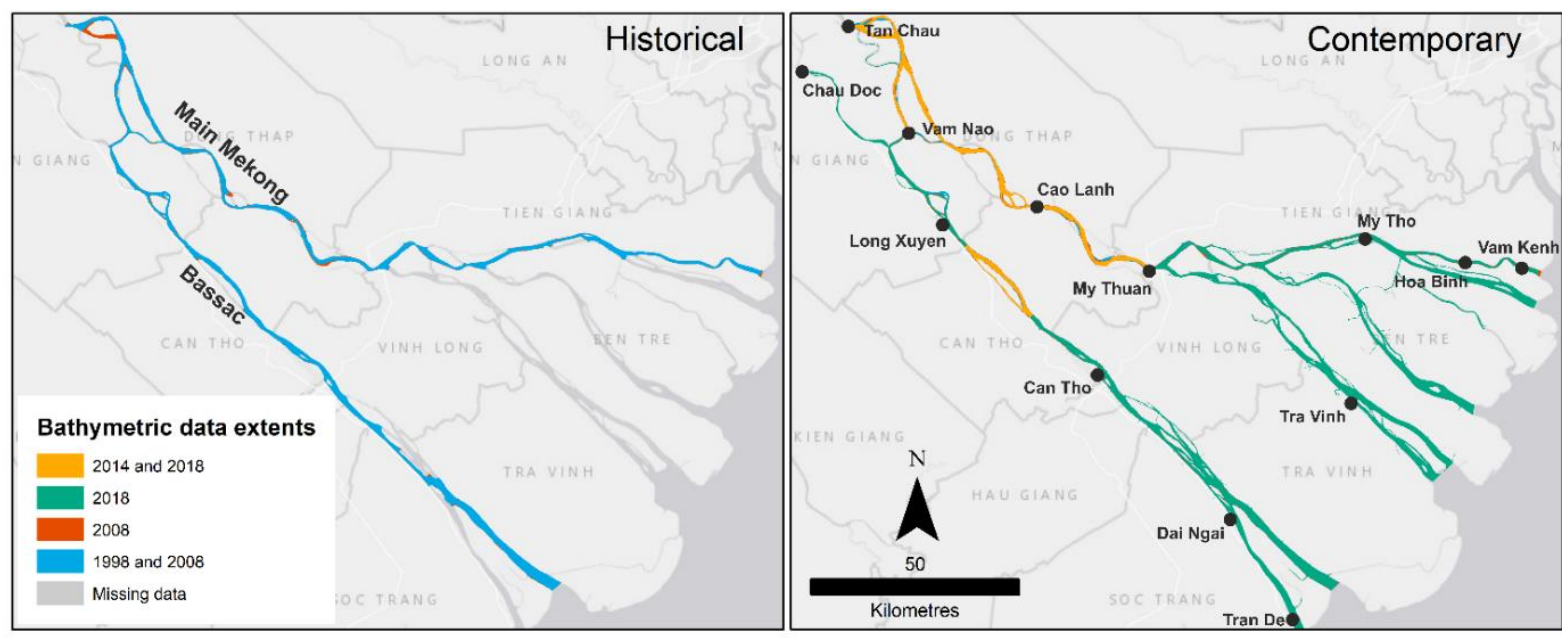

662 Extended Data Fig. 1 | Extents of the various channel survey datasets used in the study also

663 showing the locations of water level gauges (black circles) used to convert the 2018 single

664 beam echo-sounding measurements into bed elevations with respect to the Hon Dau Mean

665 Sea Level. 
Measured channel bed levels

a. 1998

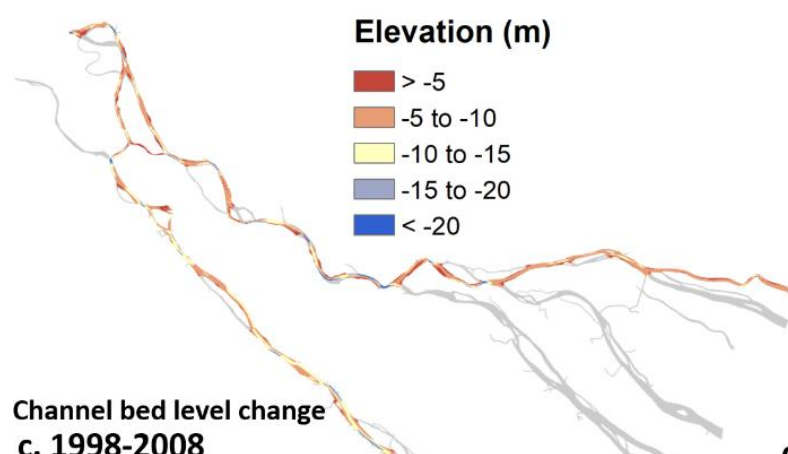

b. 2008

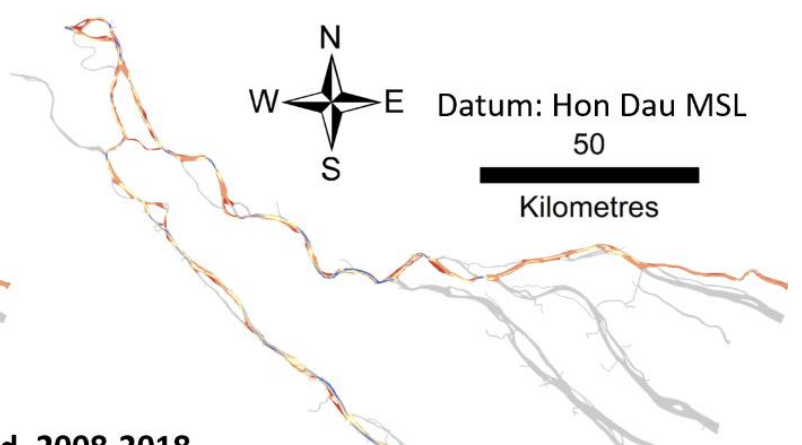

c. 1998-2008

$\mathrm{M} \times$

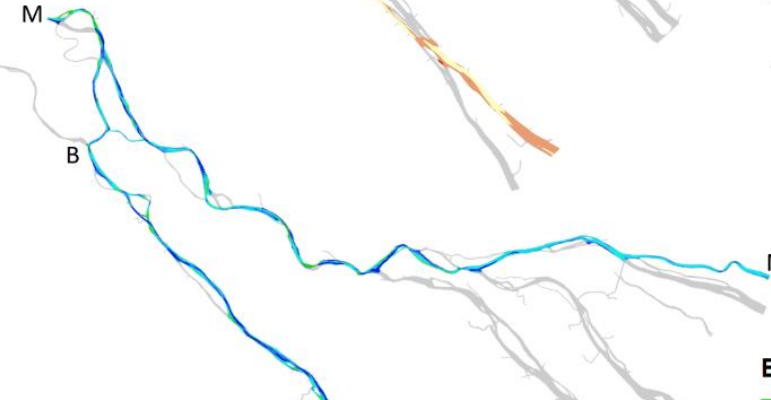

d. 2008-2018
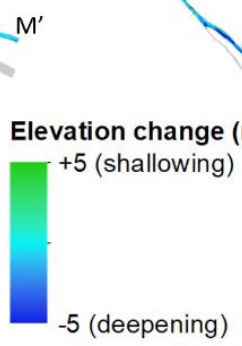
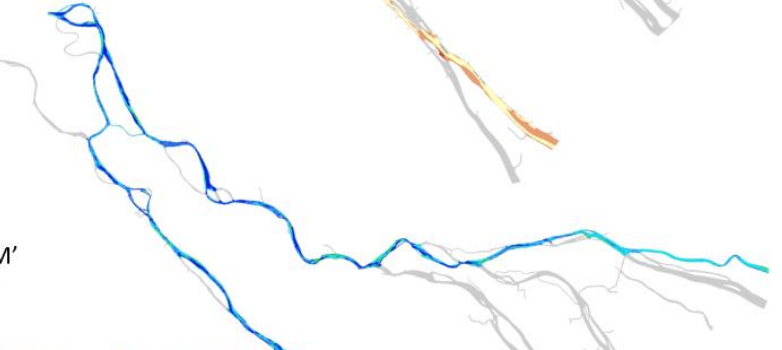

$B^{\prime}$

667 Extended Data Fig. 2 | Historical channel bed levels (referenced to Hon Dau Mean Sea Level)

and changes for the Vietnamese Mekong delta. a, 1998 bed levels of the principal delta

669 channel network. b, 2008 bed levels of the principal delta channel network. c, Channel bed

670 level change between 1998 and 2008 d, Channel bed level change between 2008 and 2018

671 (missing areas in grey). 

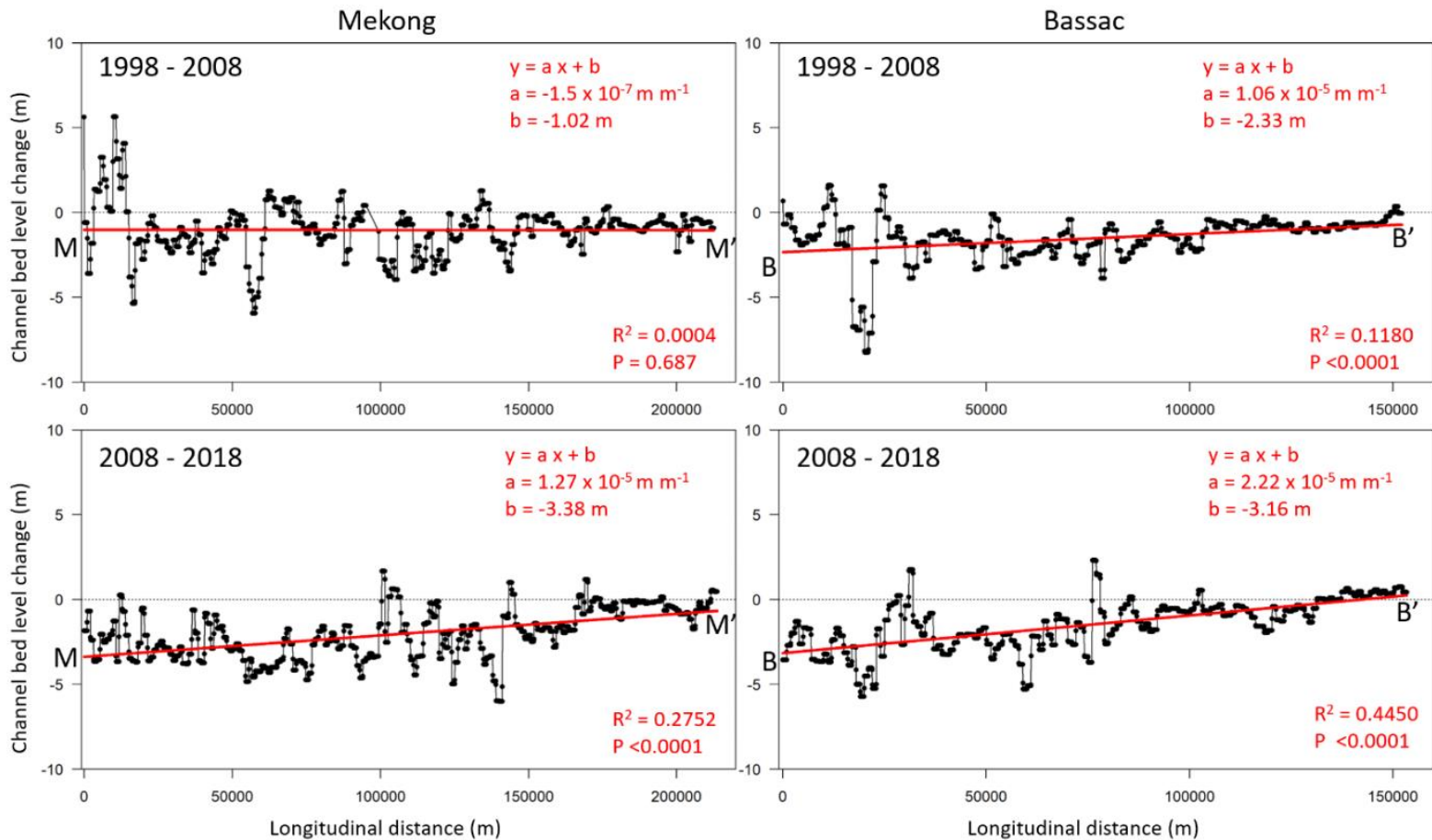

673 Extended Data Fig. 3 | Laterally averaged differences of bed levels along the main Mekong

674 (left) and Bassac (right) channels for the periods 1998-2008 (top) and 2008-2018 (bottom),

675 also showing the derived linear trends of bed-level change (red lines, with the fit parameters

676 also annotated on each subplot). 
Spatial variation of elevation change:

a. 1998-2008

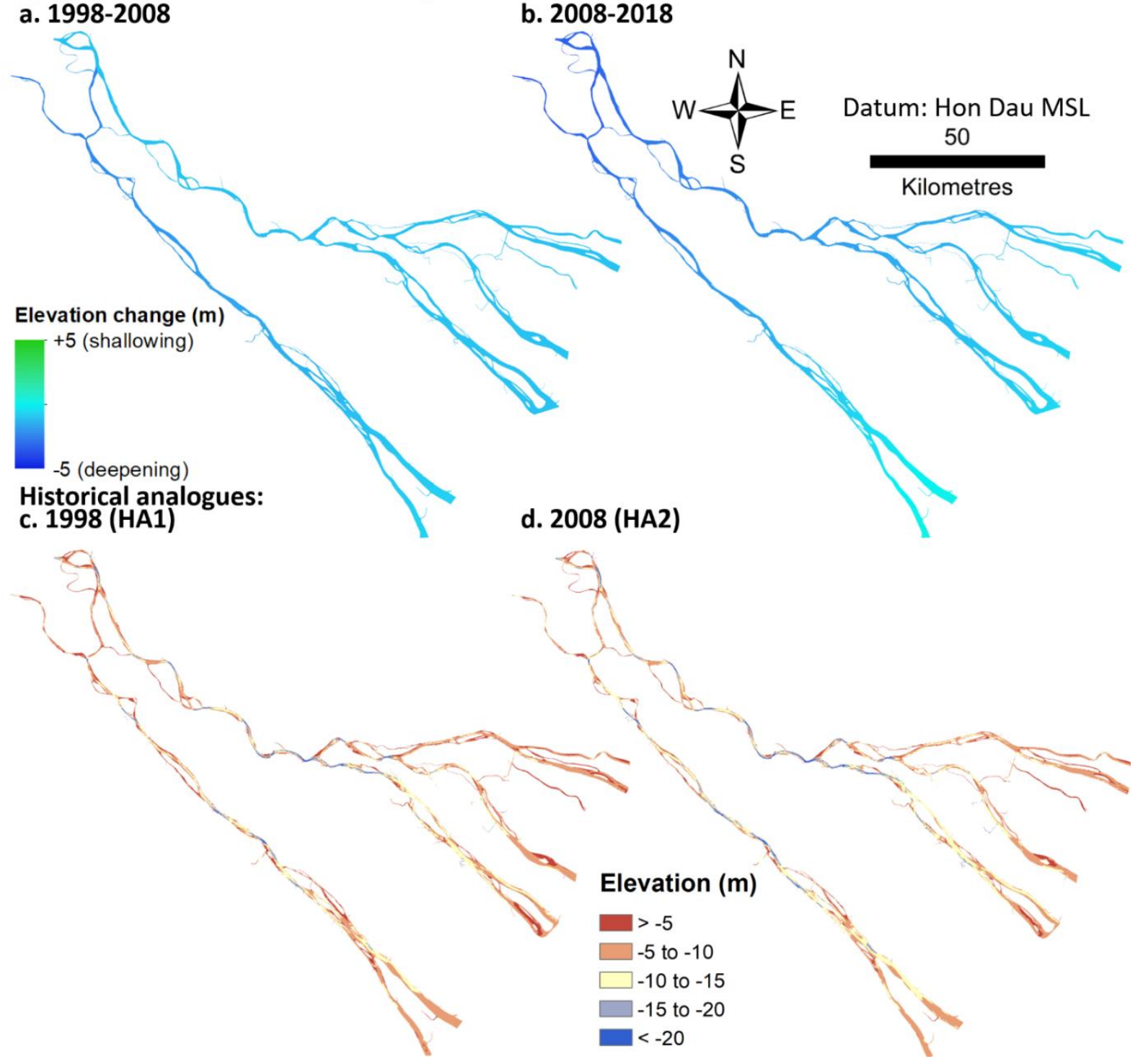

678 Extended Data Fig. 4 | Spatio-temporal variations of channel bed-level lowering and derived

679 historical analogues. a, Spatial variation of bed-level lowering for the period 1998-2008. b,

680 Spatial variation of bed-level lowering for the period 2008-2018. c, Historical delta analogue

681 for 1998 (HA1) derived from combination of the 1998-2008 data (a) with HA2. d, Historical

682 delta analogue for 2008 (HA2) derived from combination of the 2008-2018 data (b) with the

channel bed level map of 2018 (Fig. 1a). 

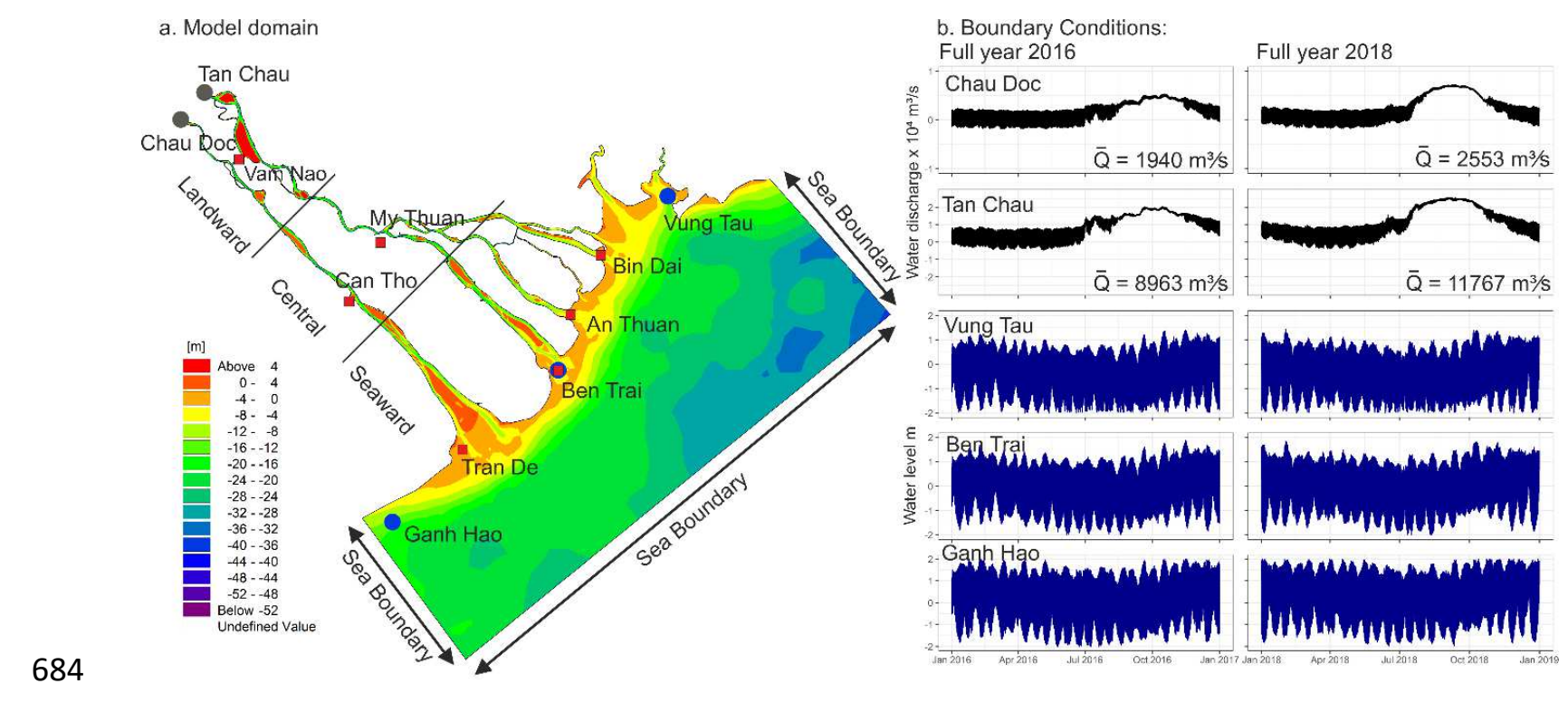

685 Extended Data Fig. 5 | Overview of the 2D hydrodynamic model of the VMD. a, Model

686 domain showing elevations relative to Hon Dau Mean Sea Level (MSL), along with details of

687 the model boundaries (black/blue circles for landward/seaward boundary condition locations)

688 and locations of hydrometric stations used in the analysis. b, 2016 and 2018 data time series

689 for discharge (black lines), with text labels indicating the mean annual discharge, and water

690 levels (blue lines) relative to Hon Dau MSL used to force the model during the calibration

691 and validation runs, respectively 


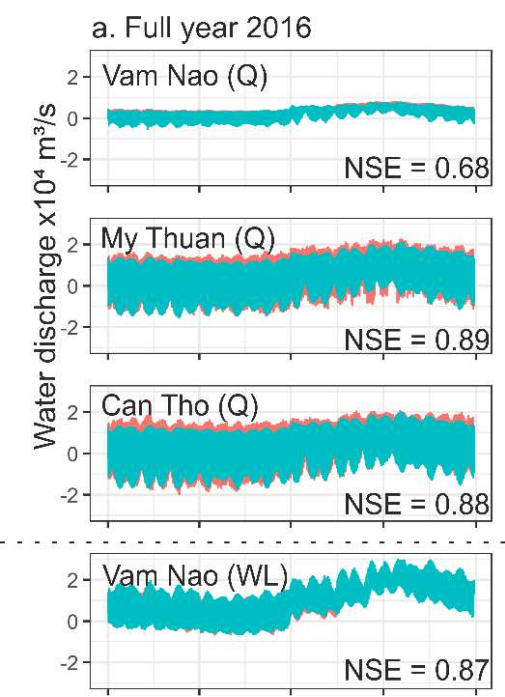

b. Dry season (1-week)
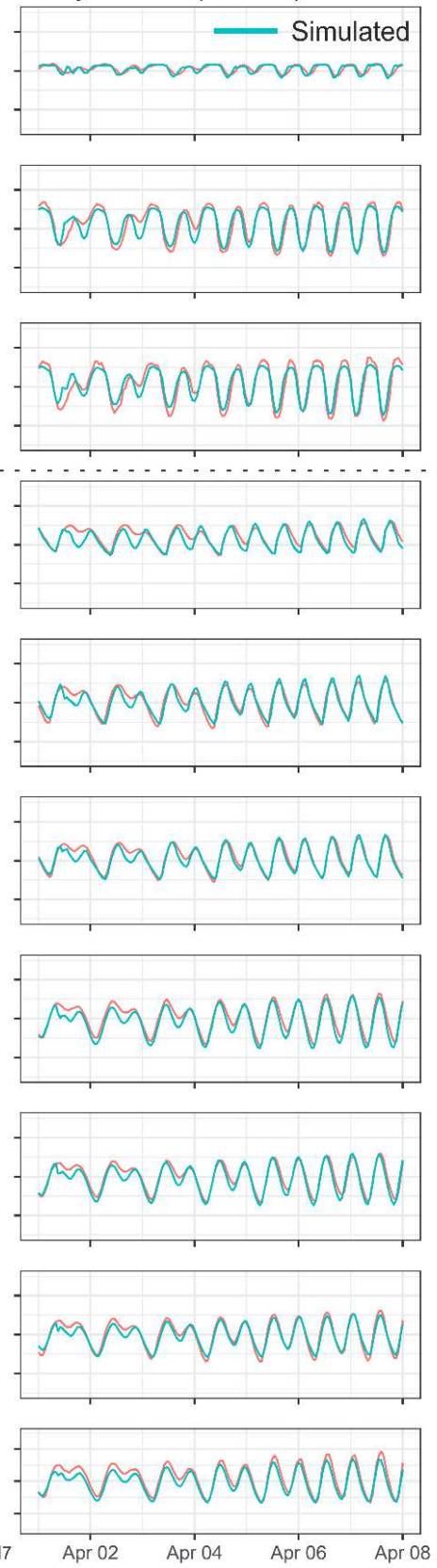

c. Flood season (1-week)
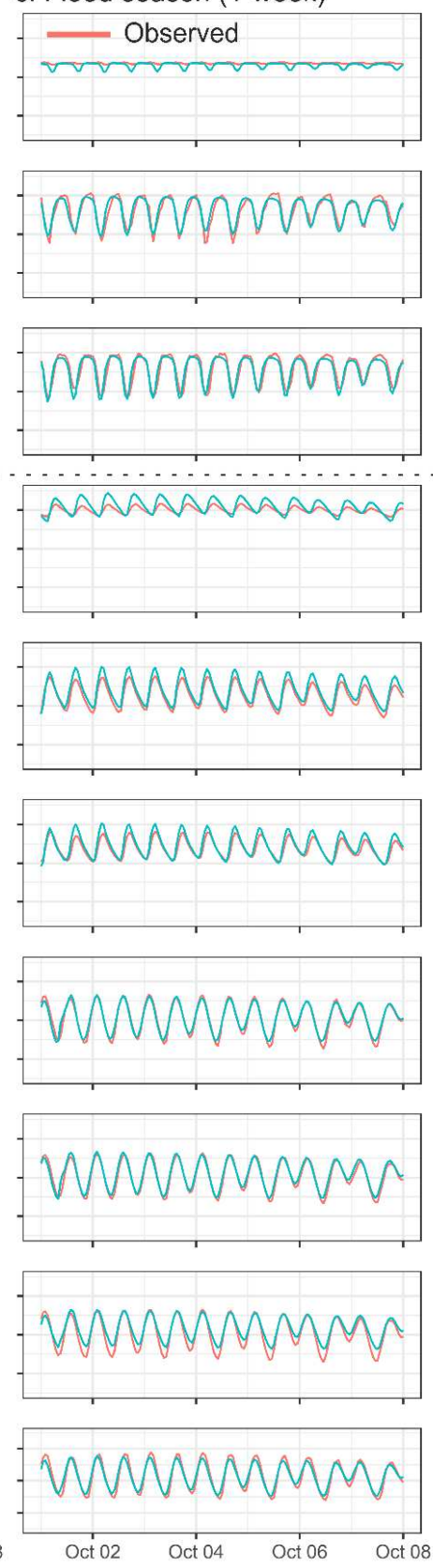

693 Extended Data Fig. 6 | Model performance for the year 2016 model calibration run. a,

694 Comparison of observations (red lines) with model predictions (blue lines) at different hydrometric monitoring stations (see Extended Data Fig. 5 for locations of these stations) generated using the 2018 bathymetry and year 2016 boundary conditions. b, detail showing 1-week long timeseries (1-7 April) during the dry season c, detail showing 1-week long timeseries (1-7 October) during the flood season. Text labels indicate the Nash-Sutcliffe model efficiency coefficient (NSE) computed for the full year data. 


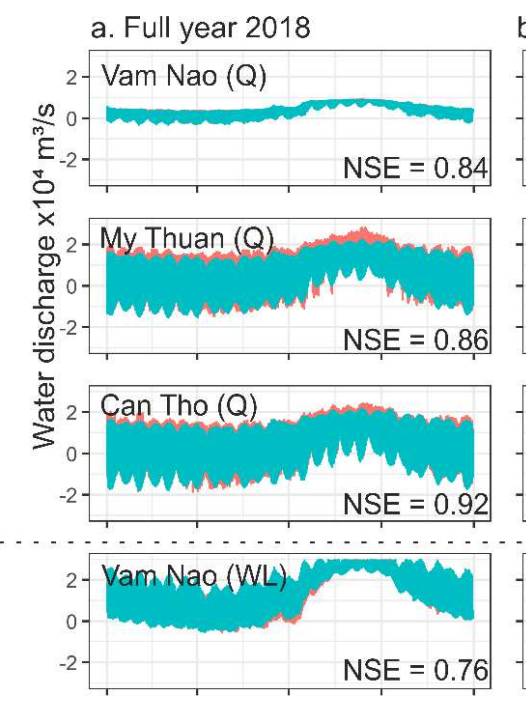

b. Dry season (1-week)
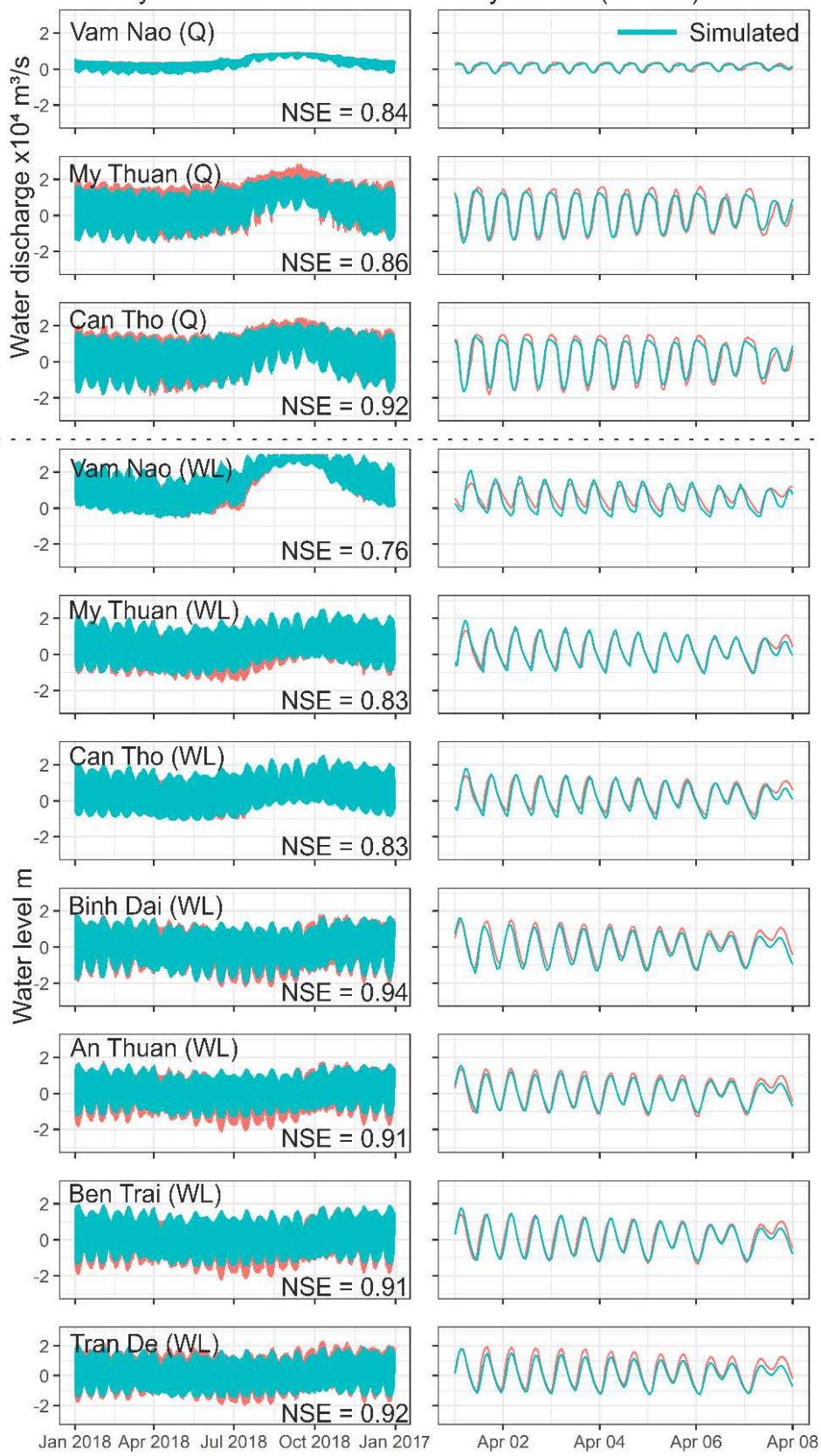
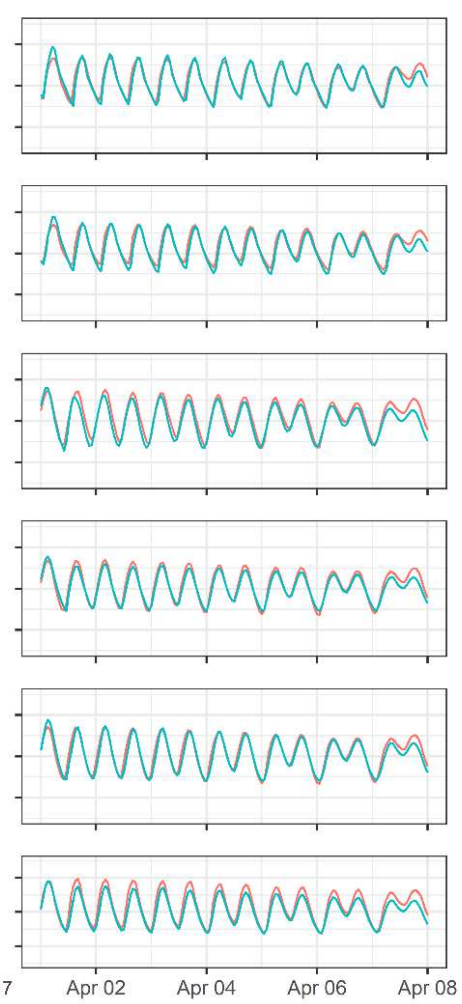

c. Flood season (1-week)
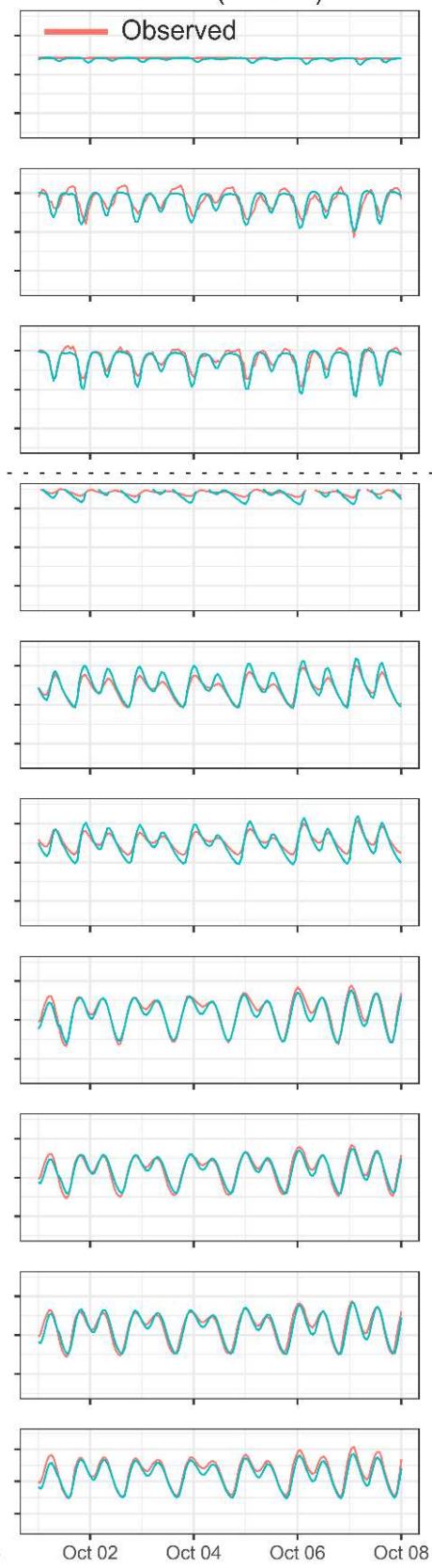

701

702

703

704

705

706

707

Extended Data Fig. 7 | Model performance for the year 2018 model validation runs. a,

Comparison of observations (red lines) with model predictions (blue lines) at different hydrometric monitoring stations (see Extended Data Fig. 5 for locations of these stations) generated using the 2018 bathymetry and boundary conditions. b, detail showing 1-week long timeseries (1-7 April) during the dry season c, detail showing 1-week long timeseries (1-7 October) during the flood season. Text labels indicate the Nash-Sutcliffe model efficiency coefficient (NSE) computed for the full year data. 

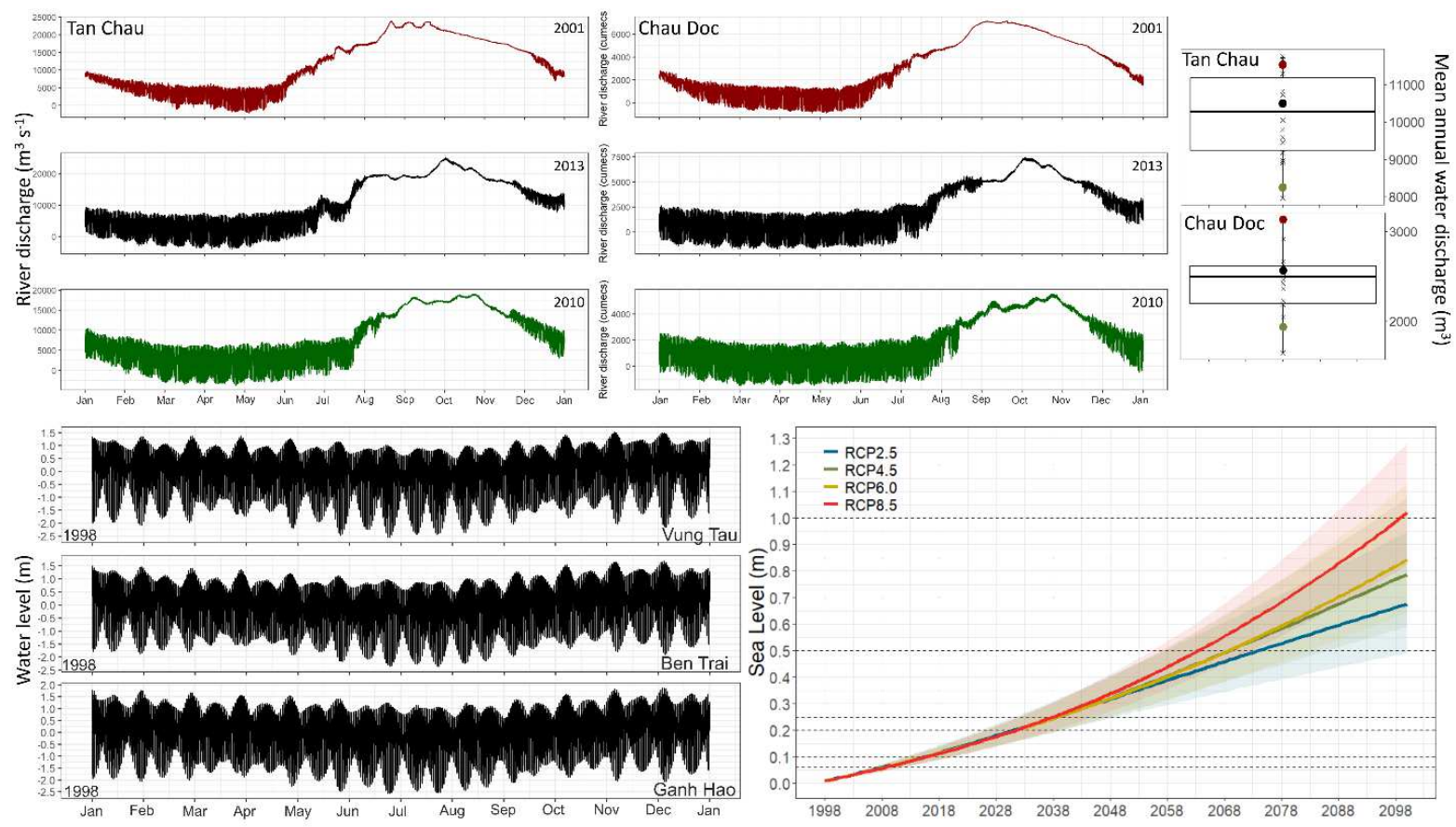

709 Extended Data Fig. 8: Boundary conditions used for the various scenarios investigated. River discharge measurements at Tan Chau and Chau Doc (see Extended Data Fig. 5 for locations of these stations) for the years 2013, 2001 and 2010 (top) have mean annual values close to the median and upper and lower bounds of the 2001-2018 range, respectively (shown in box plots). Tidal fluctuations of water levels relative to Hon Dau MSL as measured at Vung Tau,

714 Ben Trai and Ganh Hao (see Extended Data Fig. 5 for locations of these stations) for the year 1998 (bottom left) were successively offset by a eustatic sea-level rise projected by RCP scenarios (bottom right). 


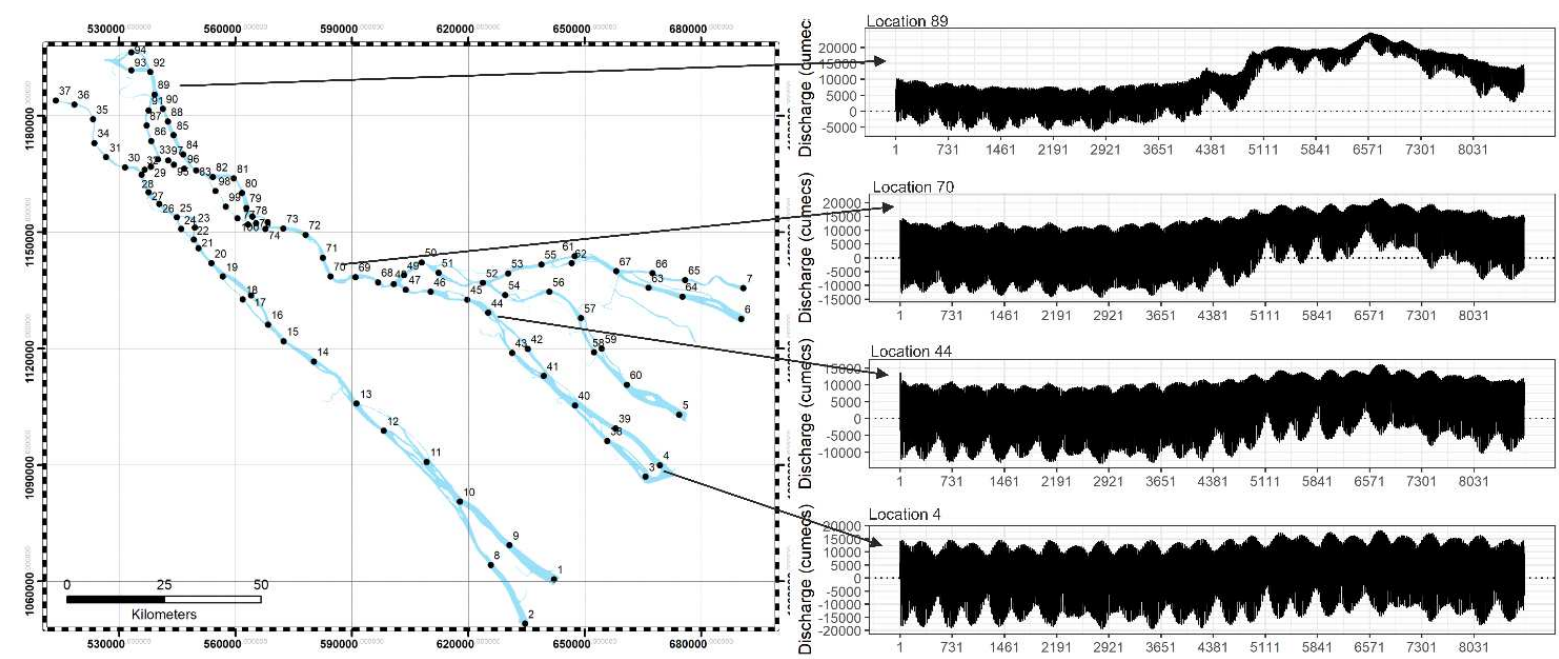

718 Extended Data Fig. 9| Locations of hydraulic model results (left) and examples of simulated

719 discharges at 4 different locations (locations 4, 44, 70 and 89), highlighting the different ratio

720 of fluvial and tidal influences (right). The discharges shown here correspond to a simulation

721 using the contemporary channel bed levels (M1), 2018 sea levels $(+0.1 \mathrm{~m})$ and the median

722 (2013) river discharge 


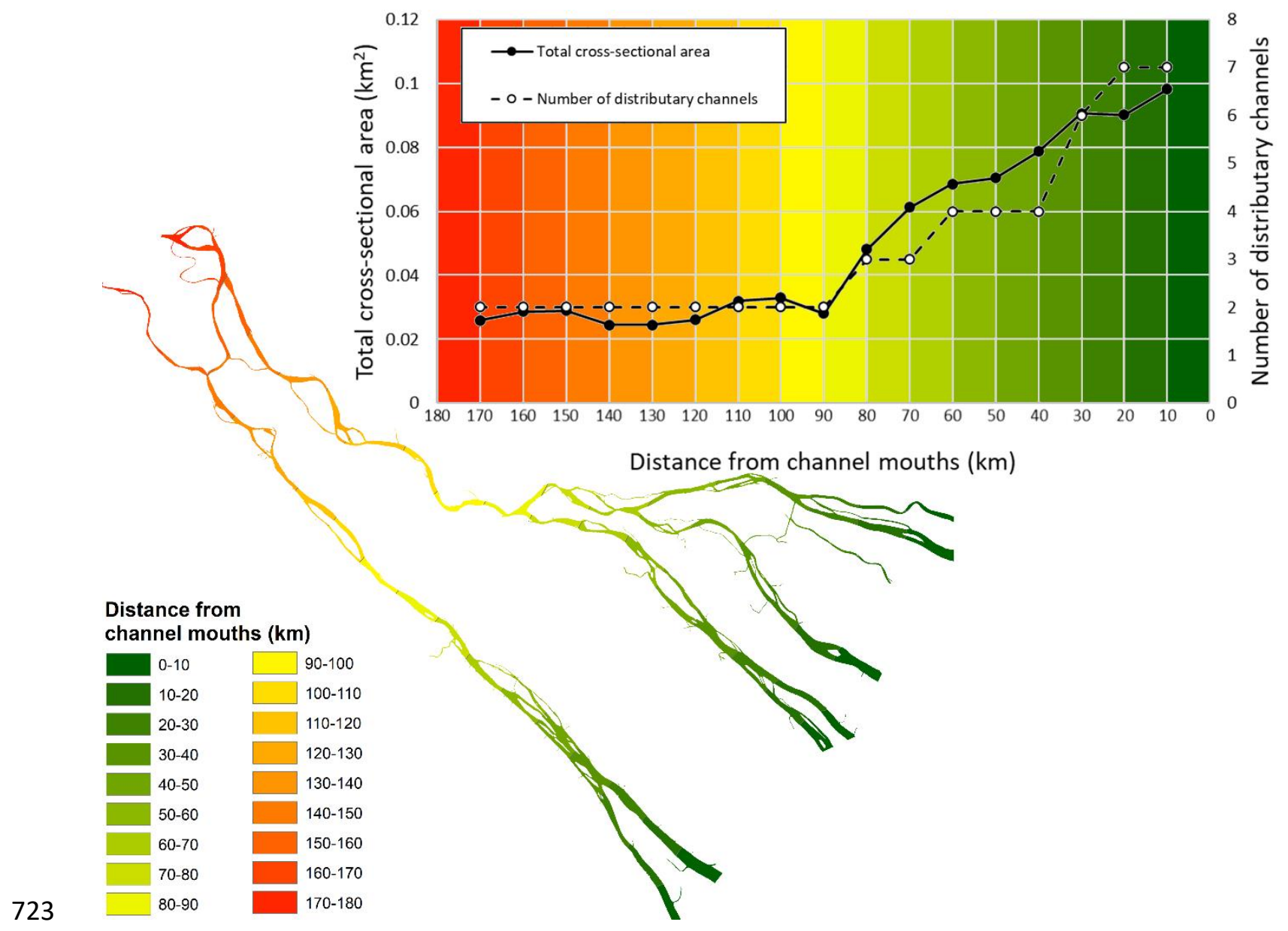

724 Extended Data Fig. 10| Total channel cross-sectional area and number of distributary

725 channels versus distance from the channel mouths. 


\section{Figures}

a Contemporary channel bed levels and historical change

C Projected channel bed levels

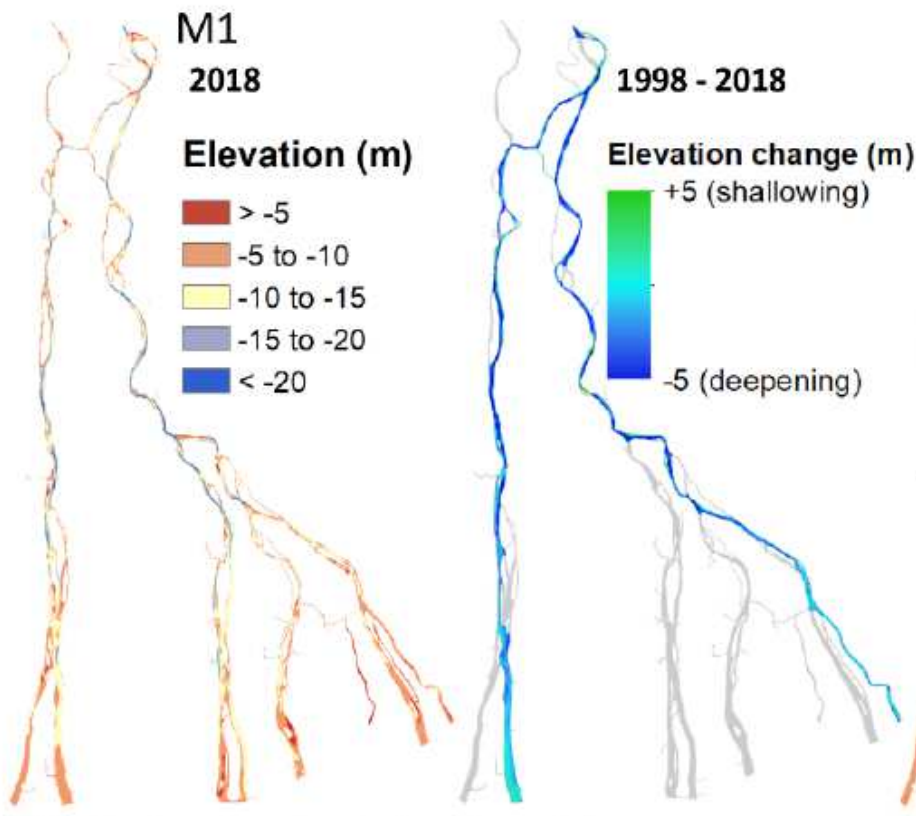

$\mathrm{M} 2$

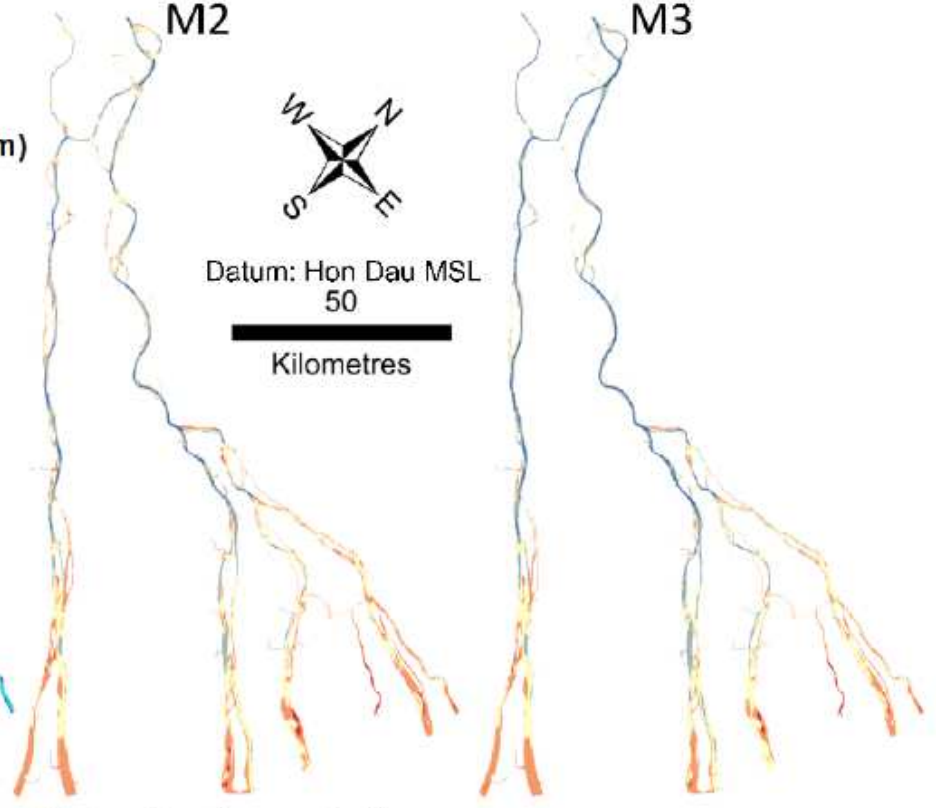

b Historical and projected sediment loss

d Trends of cumulative pressures
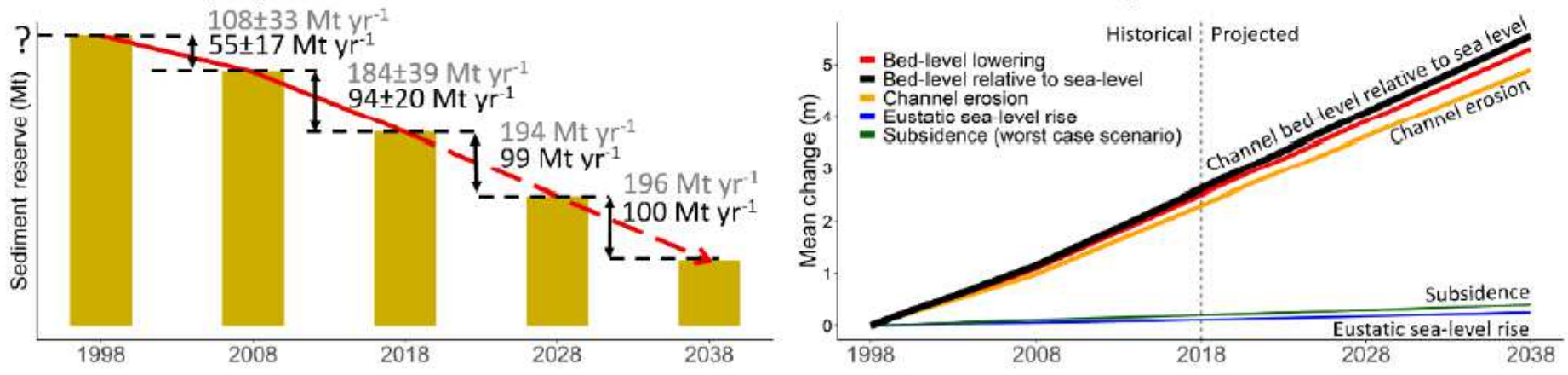

Figure 1

Evolution trajectories for the Vietnamese Mekong delta. a, Contemporary (2018) bed elevations of the principal delta channel network also showing bed-level changes relative to 1998 (missing areas in grey). b, Sediment losses computed for the historical (1998-2018) period (extrapolated to the full delta extent in grey) and linearly extrapolated 20 years into the future. c, Future delta morphologies generated via linear projected estimates of future channel evolution. $d$, Trend of channel bed-level relative to sea-level broken down into eustatic sea-level rise and channel bed lowering components, the latter being the sum of channel erosion and subsidence40. 


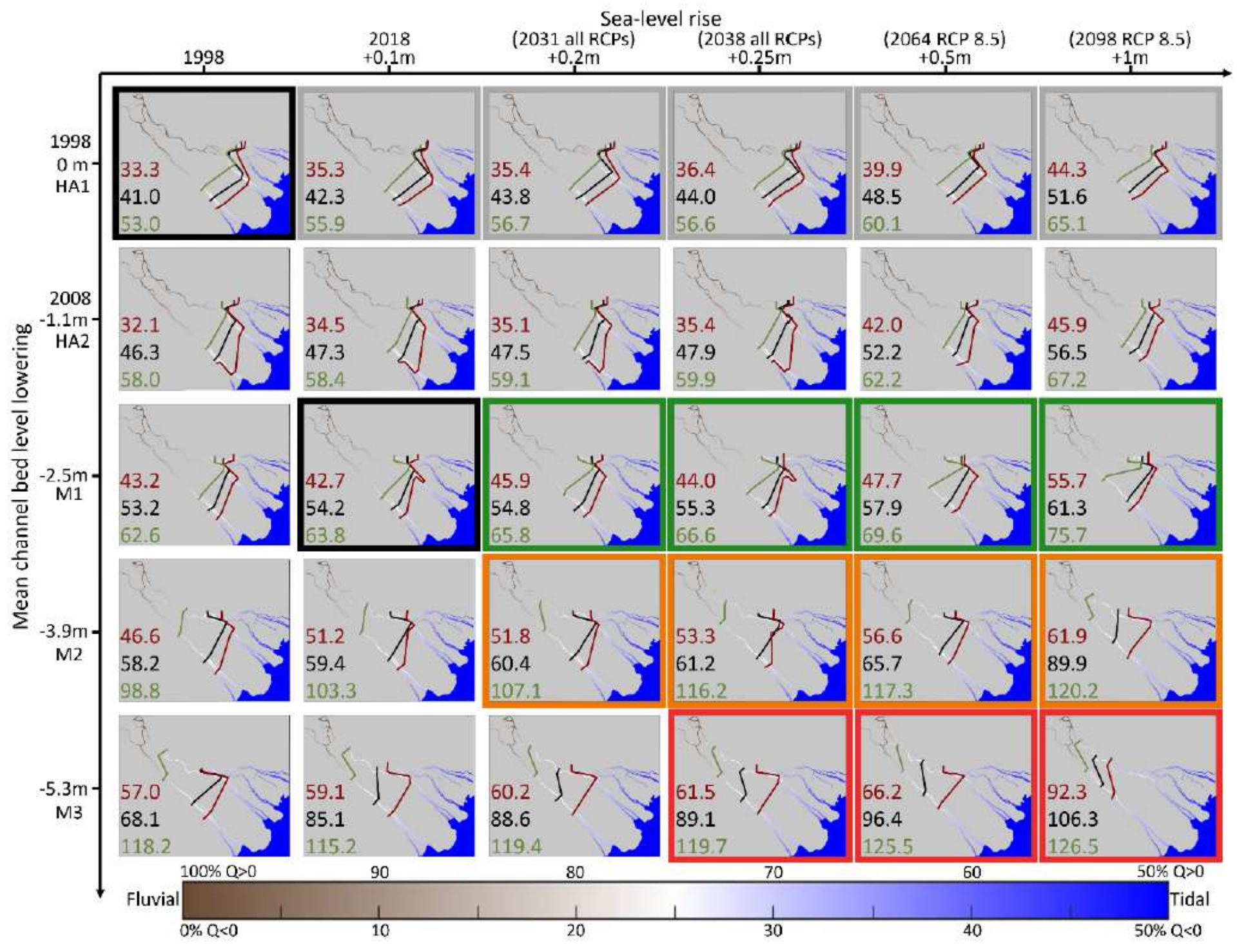

Figure 2

Simulated mean annual tidal extent. The colour scale indicates the fluvial-tidal transition (under a median annual river discharge). Green, black and red lines show the location of the tidal limit under low, median and high mean annual river discharges, respectively. Text labels indicate the tidal extent for each scenario. Sea-level rise is denoted on the horizontal axis and is relative to local mean sea-level for 1998 (see Methods). Mean channel bed lowering scenarios M1, M2 and M3 (see Methods) are denoted along the vertical axis relative to the 1998 (HA1) channel morphology. Coloured borders relate to the trajectories of Fig. 3. 


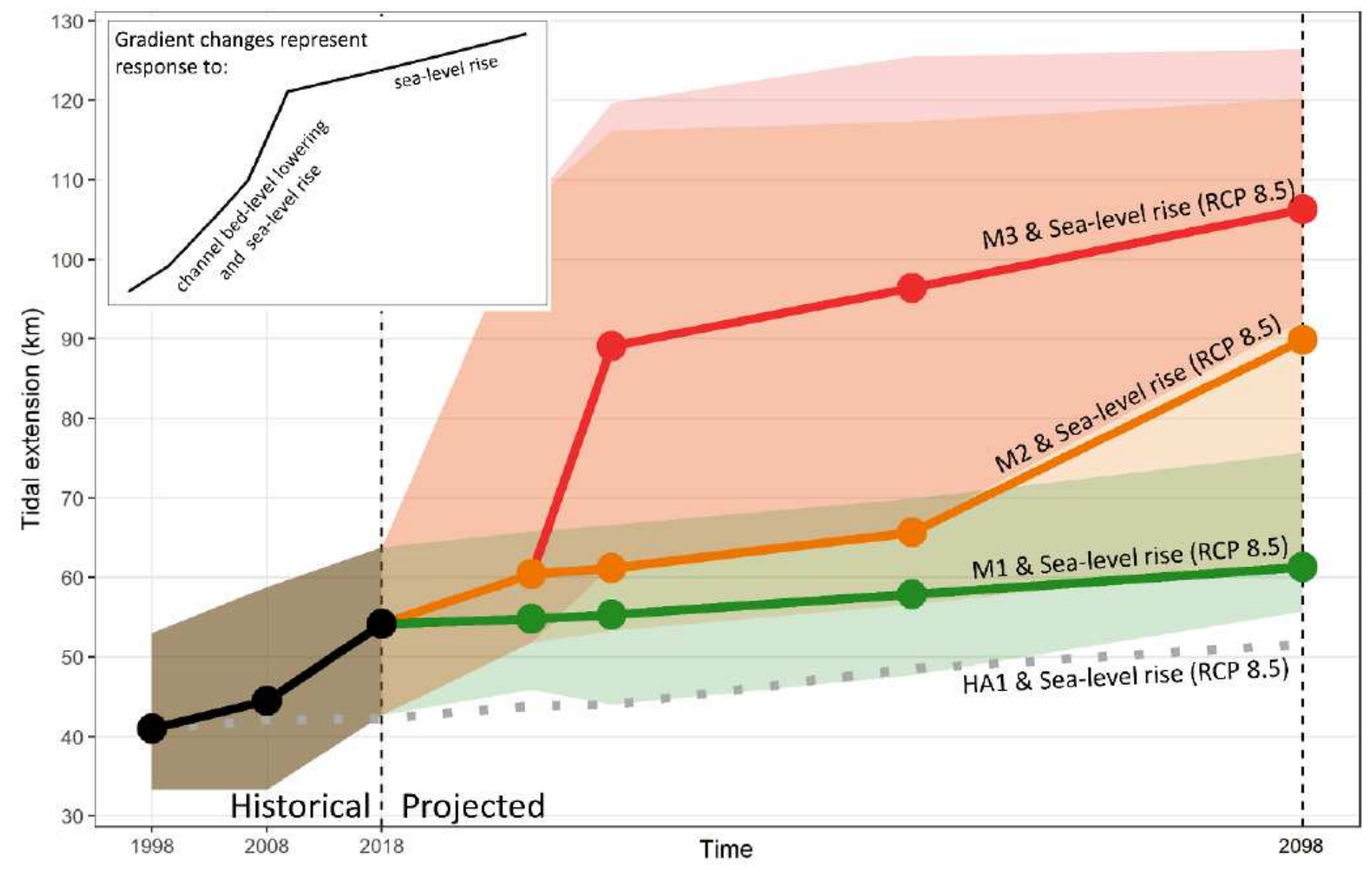

\section{Figure 3}

Future trajectories of tidal extension under the mitigation scenarios M1, M2 and M3. The black line denotes the historical trend, the grey dotted line represents a hypothetical trend (HA1) forced only by rising sea-levels with no channel change relative to 1998. Coloured lines show projected future tidal extension driven by combinations of channel bed-level lowering and rising sea-levels under the M1 (green), M2 (orange) and M3 (red) mitigation scenarios. Lines and coloured ribbons represent the median, lower and upper bounds of mean annual river discharge scenarios, respectively. Coloured circles correspond to the tidal extents indicated in Fig. 2. 